\title{
Precision agriculture technology adoption: a qualitative study of small-scale commercial "family farms" located in the North China Plain
}

\author{
Helen Kendall $^{1} \cdot$ Beth Clark ${ }^{1}$ (D) Wenjing $\mathrm{Li}^{1,2,3} \cdot{\text { Shan } \mathrm{Jin}^{1} \cdot \mathrm{Glyn} \text {. D. Jones }}^{2} \cdot$

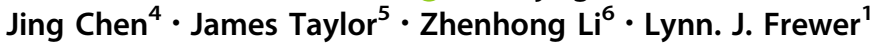

Accepted: 20 August 2021 / Published online: 12 September 2021

(C) The Author(s) 2021

\begin{abstract}
Precision agriculture (PA) technologies offer a potential solution to food security and environmental challenges but, will only be successful if adopted by farmers. Adoption in China lags behind that in some developed agricultural economies despite scientifically proven benefits of PA technologies for Chinese agriculture. Adoption is dependent on farmer attitudes and perceptions towards PA technologies. An exploratory qualitative study using in-depth interviews was conducted with Chinese arable farmers $(n=27)$ to explore their perceptions towards and adoption intentions of PA technologies in two Chinese provinces (Hebei and Shandong). A thematic analysis revealed five central themes to have emerged from the data, these were: "socio-political landscape", "farming culture", "agricultural challenges", "adoption intentions (barriers/facilitators" and "practical support mechanisms". All were likely to influence the level and rate of adoption of PA technologies amongst family farmers in China. The research revealed an openness to the potential of PA technologies amongst family farmers, although there was heterogeneity in the perceptions of PA technology and willingness to adopt. Improved rates of adoption will be achieved by reducing the barriers to adoption, including the need for low-cost PA applications that can be applied at small scale, improved information provision, financial support mechanisms including more accessible subsidies and credit, and reliable, regulated and affordable service provision.
\end{abstract}

Keywords Precision agriculture $\cdot$ Farmer perceptions - Adoption motivations - China · Risk · Benefits

\section{Introduction}

\section{Overview}

Precision agriculture (PA) is being implemented globally as an agricultural data management strategy across many agronomic contexts. It is an approach that takes account of temporal and spatial variability to support management decision-making to enable 
improved resource use efficiency, productivity, quality, profitability and sustainability of agricultural production (International Society of Precision Agriculture, no date). The use of PA technologies in particular is aimed at ensuring sustainable intensification across all aspects of agricultural production, whilst reducing its environmental impacts (Gebbers \& Adamchuk, 2010; Li et al., 2020). Their utility in relation to improved food security and environmental protection has been well documented (Cheema \& Khan, 2019; Gebbers \& Adamchuk, 2010; Mikula et al., 2020; Phillips, 2014). PA can be viewed as a 'toolkit' from which farmers choose what they (perceive to) need (Lowenberg-DeBoer \& Erickson, 2019). Although a clear definition of what technologies are included in PA is still required (Lowenberg-DeBoer \& Erickson, 2019; Say et al., 2018) broadly technologies can be classified into: data collection technologies, including, global satellite positioning (GNSS: see Stombaugh, 2018); remote sensing technologies (Wachowiak et al., 2017), soil sampling and mapping, data processing and decision-making technologies e.g., geographical information systems (GIS) and sensor networks (Jawad et al., 2017), and; application technologies, including, variable rate technologies (VRT) (Wandkar et al., 2018).

PA technologies are designed to deliver three fundamental benefits to farmers and society: (1) economic benefits through reductions in farm expenditure via the controlled application of agricultural inputs (Tey et al., 2017); (2) increased production levels due to targeted management of in-field (or intra-animal) variability (Schimmelpfennig, 2016) and; (3) environmental benefits through the precise application of agrichemical applications (such as fertilisers, pesticides or antimicrobials), which will also increase compliance with national/global environmental legislation (Ma et al., 2014). Technology uptake in low resource economies falls behind more advanced agricultural economies despite their considerable potential to increase efficiencies in production, inclusion and participation in global markets and improve rural livelihoods (Deichmann et al., 2016; Pathak et al., 2019). There is scope for the adoption of small, low-cost PA technologies and there are examples of PA uptake in Argentina, Brazil, India and South Africa (inter alia (Finger et al., 2019; Say et al., 2018)). Rates of PA adoption vary considerably globally, with uptake in China recognised to fall significantly behind Europe and Australia (Chen et al., 2014; Say et al., 2018). The culmination of social, environmental, political and production pressures identify China as a country with significant potential to benefit from the adoption of PA technologies and make the country an interesting and timely example for their adoption ( $\mathrm{Li}$ et al., 2019, 2020).

\section{The potential of precision agricultural technologies in China}

Intensification of production has historically dominated Chinese agriculture policy (Hauptman, 2018). Chinese agricultural production is subject to interacting pressures including, inter alia; dwindling natural resources, environmental degradation, climate change, and over-reliance on agrichemicals (Cui et al., 2014; Hauptman, 2018). Social pressures include population growth, rapid urbanisation and increasing socio-economic rural urban divides, and changing consumer preferences (Cui et al., 2018; Qian et al., 2016).

A variety of policy initiatives have been introduced over the last 50 years to address China's food security pressures and modernise its approach to agriculture (Zhong \& Zhu, 2017). These include reducing the ecological impacts of farming by introducing a cap on fertiliser usage (Lin, 2020). Widespread agricultural technology adoption is recognised as having a fundamental role to play in the modernisation process, and will contribute to 
securing China's future economic growth (Liu et al., 2013). It represents a key component of China's latest 13th, Five-Year Plan that represents the countries social and economic development initiatives, and features in the national 863 Programme (State High-Tech Development Plan). PA is currently concentrated on large-scale commercial agricultural operations, which only account for $0.0007 \%$ of all farms in China (Clark et al., 2018). This may be in part due to lack of IT infrastructure to support PA technologies, coupled with a lack of capacity both within the industry and intended population, to exploit their potential at scale (Li et al., 2019).

\section{Agricultural landscape in China}

The Chinese agricultural landscape is characterised by the fragmentation of farmland and a preponderance of small subsistence farms (Table 1). This is a legacy of the former Household Responsibility System (HRS) which represented a move away from collective farming and gave individual households autonomy over allocated plots for substance farming, commonly known as responsibility land (Table 2 summarises key Chinese agricultural policy reforms and their impacts). Agricultural policy reforms introduced in the 1990 s and early 2000s aimed to radically transform the agricultural landscape by creating formalised markets for land transfer to facilitate larger scale, commercial farming to meet food demand (Sausmikat, 2015). In creating land markets, the value of agricultural land and the agri-business sector increased, whilst also increasing the suitability of the land for the adoption of advanced agricultural technologies. This provided an opportunity for some farmers to leave agricultural production and pursue alternative employment, whilst for others, renting land from others provided a means of producing commercially. "Family farms" in this sense are farms that operated at commercial scale but are predominantly operated by a single family. Land comprises of a family's responsibility land plus land they have tenanted from others. In 2016, 30.7 million ha (460 million mu) of land had been transferred in this way, accounting for more than a third of all total agricultural land area. This indicates that small non-commercial farming is diminishing and there is an observable growth in the number of larger "family farms" (Xinhuanet, 2020), although still only

Table 1 Characterization of Chinese farms at different scales

\begin{tabular}{|c|c|c|c|c|}
\hline Scale & Description & $\begin{array}{l}\text { Number } \\
\text { (households) }\end{array}$ & $\begin{array}{l}\text { Percentage } \\
\text { of farms in } \\
\text { China }\end{array}$ & $\begin{array}{l}\text { Average } \\
\text { size/ha }\end{array}$ \\
\hline Small farms & $\begin{array}{l}\text { Very small operations for personal food } \\
\text { production }\end{array}$ & $\begin{array}{l}266.07 \\
\text { million }\end{array}$ & $99.2 \%$ & 0.41 \\
\hline $\begin{array}{l}\text { Farm } \\
\text { cooperatives }\end{array}$ & $\begin{array}{l}\text { Collaborations between groups of family } \\
\text { famers to increase scale to improve } \\
\text { commercial output and economic } \\
\text { functioning }\end{array}$ & 1.39 million & $0.52 \%$ & \\
\hline Family farms & $\begin{array}{l}\text { Farms at commercial scale (typically) } \\
\text { managed and predominantly operated by a } \\
\text { single family }\end{array}$ & 0.88 million & $0.33 \%$ & 13.38 \\
\hline $\begin{array}{l}\text { Large } \\
\text { government/ } \\
\text { state managed } \\
\text { farms }\end{array}$ & $\begin{array}{l}\text { Typically state run farms where it is easy to } \\
\text { adopt PA in line with emerging Chinese } \\
\text { policy }\end{array}$ & 1789 & $0.0007 \%$ & \\
\hline
\end{tabular}

Table reproduced with permission from Clark et al. (2018) 
Table 2 Historic agricultural policies and their impact

\begin{tabular}{|c|c|c|}
\hline Policy & Description & Impact \\
\hline $\begin{array}{l}\text { Household } \\
\text { reasonability } \\
\text { system (HRS) }\end{array}$ & $\begin{array}{l}\text { HRS represented a move away from collective } \\
\text { farming (team-based system) and gave } \\
\text { individual households responsibility for their } \\
\text { land, creating millions of smallholders. Under } \\
\text { the HRS farmers had limited ownership rights } \\
\text { over the land that they famed and no formal } \\
\text { means of transferring ownership to others }\end{array}$ & \multirow{3}{*}{$\begin{array}{l}\text { Abolishing the HRS system, } \\
\text { increasing tenancy duration and } \\
\text { creating land markets has } \\
\text { facilitated land-transfer, increased } \\
\text { the value of agricultural land and } \\
\text { the agri-business sector, whilst also } \\
\text { increasing the suitability of the } \\
\text { land for the adoption of PA } \\
\text { technologies. Although, this has } \\
\text { resulted in farmers managing land } \\
\text { to which they have no historic } \\
\text { connection or may be farming } \\
\text { fragmented and discontinuous } \\
\text { plots rather than larger } \\
\text { management zone (He \& Ye, 2014; } \\
\text { Liang \& Wu, 2014; Liu, 2014; } \\
\text { Qian et al., 2016) }\end{array}$} \\
\hline Land tenure & $\begin{array}{l}\text { Short tenures (2-3 years base) resulted in lack } \\
\text { of stability in farming, rural poverty, high } \\
\text { rates of rural-urban migration, and limited } \\
\text { finical investment by farmers in their land and } \\
\text { production methods (Gao et al., 2017). These } \\
\text { were extended in the 1990s to increase } \\
\text { farmer's stability, improve scope for } \\
\text { investment and prosperity through farming }\end{array}$ & \\
\hline Land transfer & $\begin{array}{l}\text { In } 2002 \text {, a land transfer market in China was } \\
\text { formalised, allowing farmers to transfer land } \\
\text { during their land lease periods, promoting the } \\
\text { amalgamation of small farms into larger } \\
\text { management zones }\end{array}$ & \\
\hline
\end{tabular}

Adapted from Clark et al. (2018)

accounting for a small proportion of total agricultural holdings (approximately $0.33 \%$ ) (Xinhuanet, 2020).

Whilst land transfer policies have been a fundamental component of China's agricultural modernisation planning (Table 2), for famers that have acquired land it creates additional challenges and presents further barriers to PA adoption. For example, farmers are managing land to which they have no historic connection or may be farming fragmented and discontinuous plots rather than larger management zones. This hinders the adoption of more sophisticated PA technologies that are currently designed for large continuous land areas, making application on small plots challenging (Clark et al., 2018; Kendall et al., 2017; Li et al., 2019). Moreover, the creation of land markets has aided socio-economic trends, including increased levels of rural to urban migration, allowing farmers to transfer responsibility land to others to pursue higher earning employment opportunities in cities (He \& Ye, 2014; Liang \& Wu, 2014; Liu, 2014). The result of which has been increased ageing demographics in rural communities, reduced agricultural labour pools and increased associated labour costs.

\section{Adoption motivations and the importance of stakeholder engagement}

The adoption of PA technologies requires farmers to change their existing and often historic agricultural practices. There is a broad literature that has explored the factors influencing farmer adoption of PA technologies, although much of the research conducted to date has explored drivers of uptake in developed agricultural economies, predominantly North America, Europe and Australia (for reviews see for example Hasler et al., 2017; 
Pathak et al., 2019; Tey \& Brindal, 2012). Limited research has been conducted to understand the adoption trajectories of PA technologies in developing agricultural economies and to the best of the authors knowledge, this includes research conducted with Chinese farmers to explore their attitudes towards, and the factors influencing, more widespread adoption in Chinese agriculture. An overview of research that has sought to identify the factors influencing farmer and landowner uptake of PA technologies is provided in Table 3 and highlights three primary factorial influences (internal, external and technology) and geographical region where research has been identified to influence adoption.

It is unlikely that farmer adoption motivations are influenced by one single factor, rather they are driven by a combination of each of these three aforementioned influences which are also likely to be context specific and subject to change over time. Adoption is also potentially dependent on the level of behavioural change required by the adopter, i.e., the extent to which a new technology is "disruptive" requiring a fundamental change to their existing behaviour, or "continuous" requiring incremental behaviour change or offering benefits that complement existing farming practice (Hasler et al., 2017). Continuous technologies are more easily integrated into existing practices as they do not require significant behaviour change (Clark et al., 2018; Kendall et al., 2017).

Research has been conducted to develop PA applications and evidence their benefits for Chinese agriculture (see for example Gao et al., 2017; Han et al., 2019; Huang et al., 2018; Jihua et al., 2014; Peng et al., 2014; Zhao et al., 2017)). However, there is limited social research conducted in China that specifically explores the factors influencing the adoption of PA technologies, the extent to which existing factors apply in the Chinese agronomic, policy and cultural contexts. This research therefore adopted an interpretivist approach, using in-depth qualitative interviews to explore the views of Chinese family farmers, generate nuanced understandings of their perceptions of, and attitudes towards, PA and identify the factors that promote or inhibit adoption. The qualitative approach permitted a comparative exploration of factors and concepts that have been shown to influence uptake globally (Table 3) and explore the extent to which these have relevance for the Chinese context. Adoption of technologies, particularly where current levels of adoption are low, requires the inclusion of stakeholders in the research and development process (Galindo et al., 2012; Raley et al., 2016). This ensures that technologies align with the needs, priorities and preferences of end-users, avoids any unintended consequences, and increases adoption (Clark et al., 2018). Understanding the factors influencing adoption from the enduser perspective is therefore important for scientists, researchers, educators, agricultural extension services providers designing, trailing and suppling PA to Chinese family farmers. It also has wider relevance to those with an interest in developing agricultural economies and small-scale farming. This will support the development of PA approaches and the design of initiatives that promote widespread uptake (Wossen et al., 2015).

Three primary research aims were identified for exploration in the qualitative study:

1. To identify current agricultural challenges and the corresponding solutions from the perspective of Chinese farmers;

2. To understand Chinese farmers' perceptions of, and attitudes towards, different PA technologies and;

3. To explore the barriers to, and facilitators of, Chinese farmers' adoption of agricultural technologies and services. 


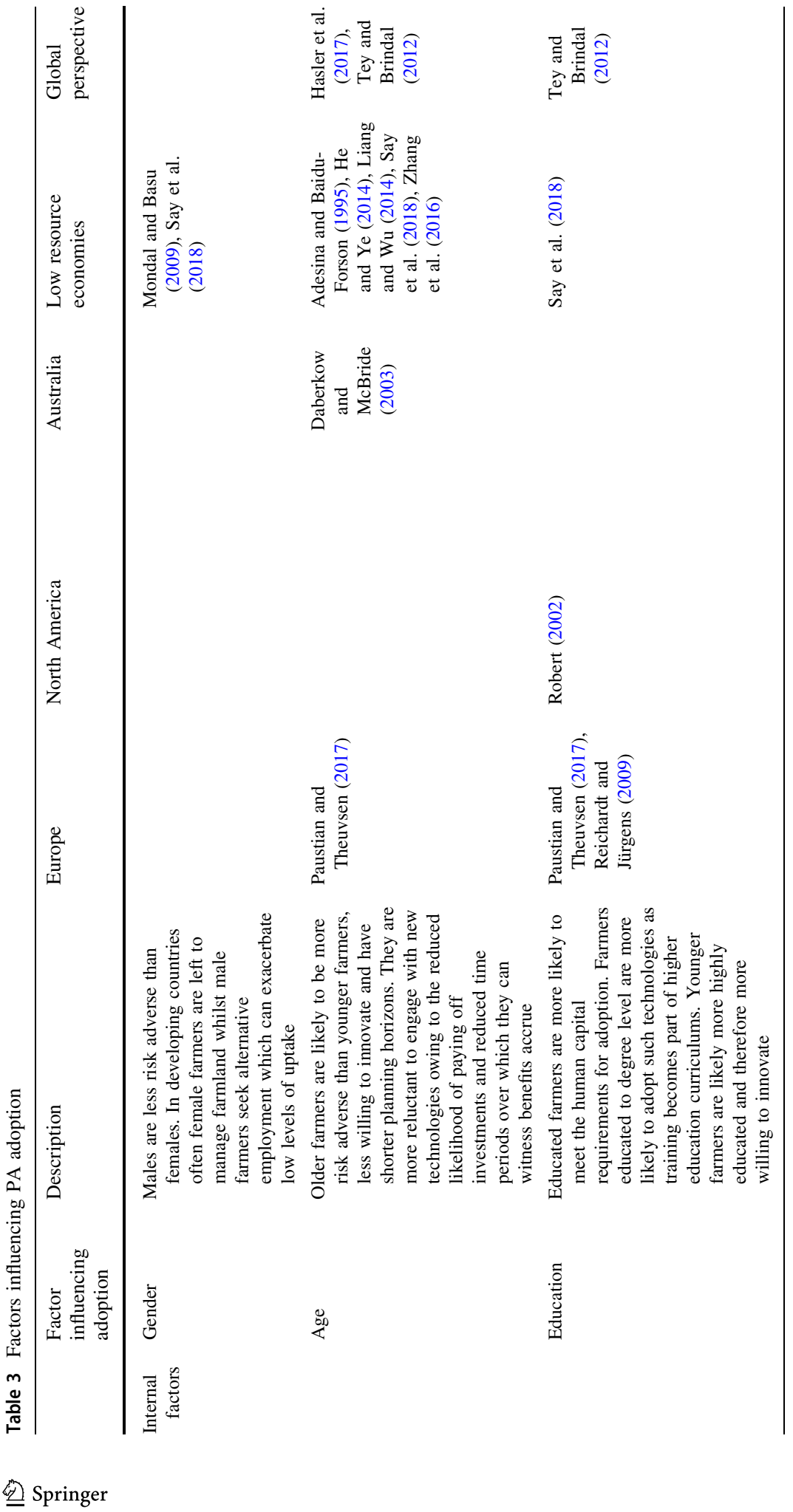




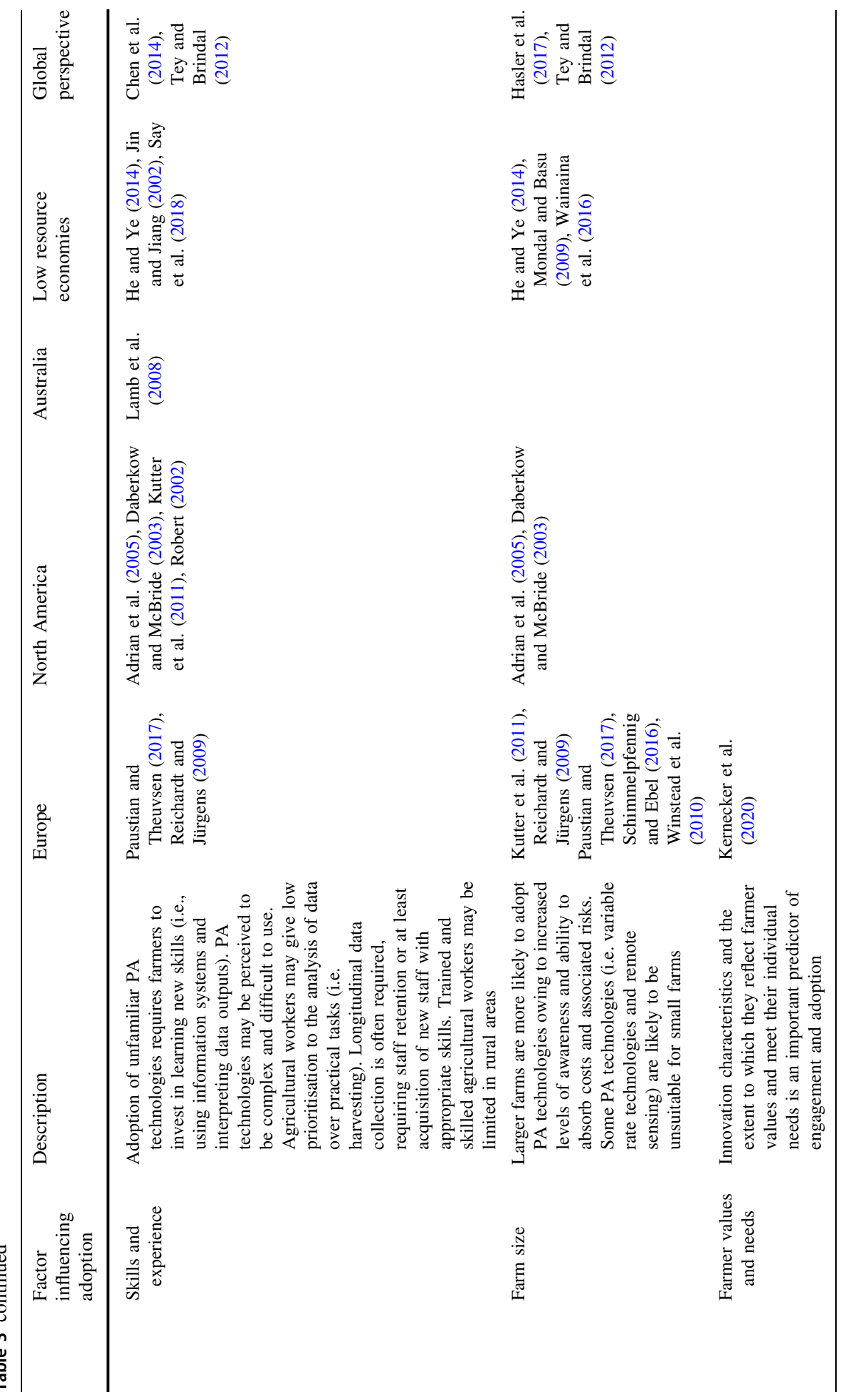




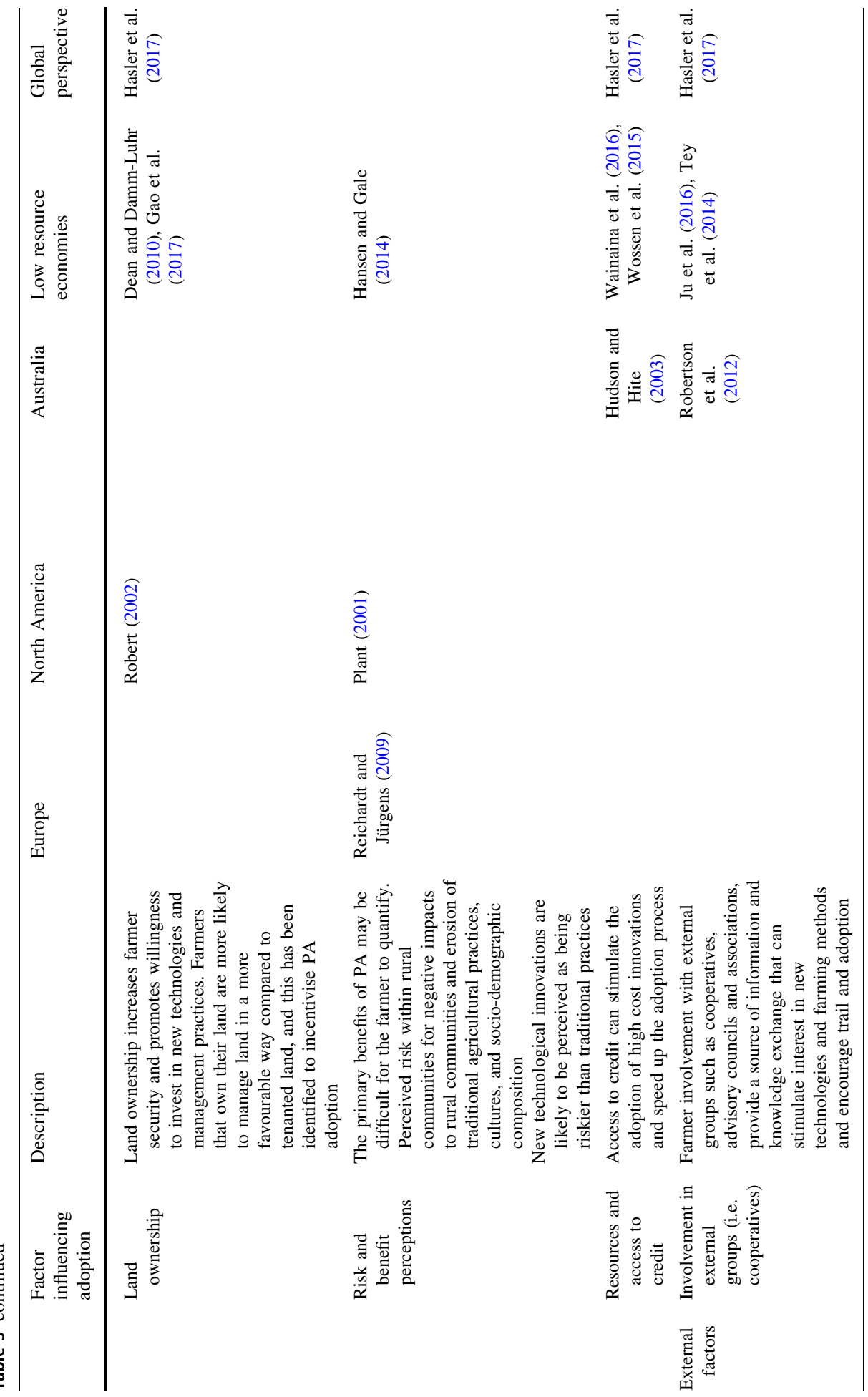




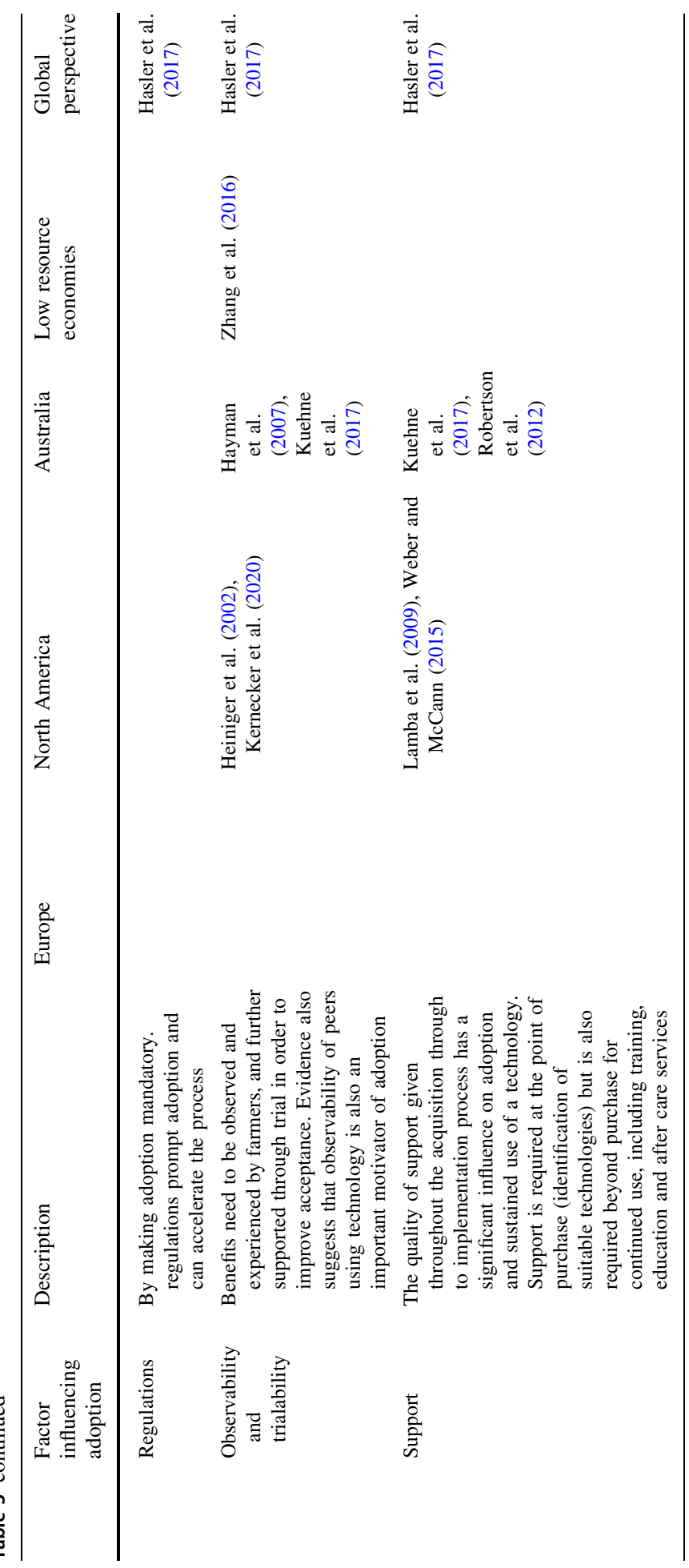




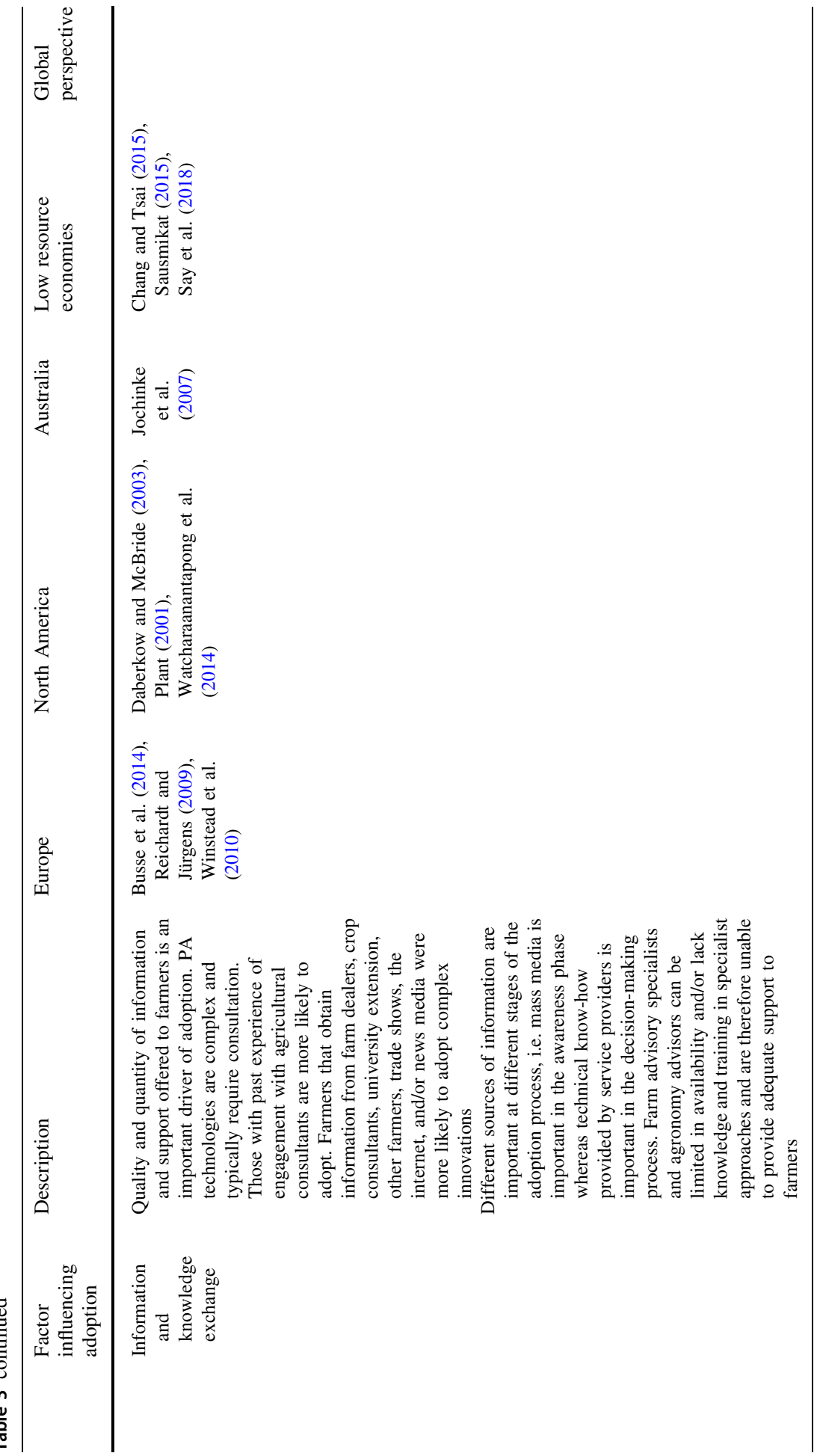




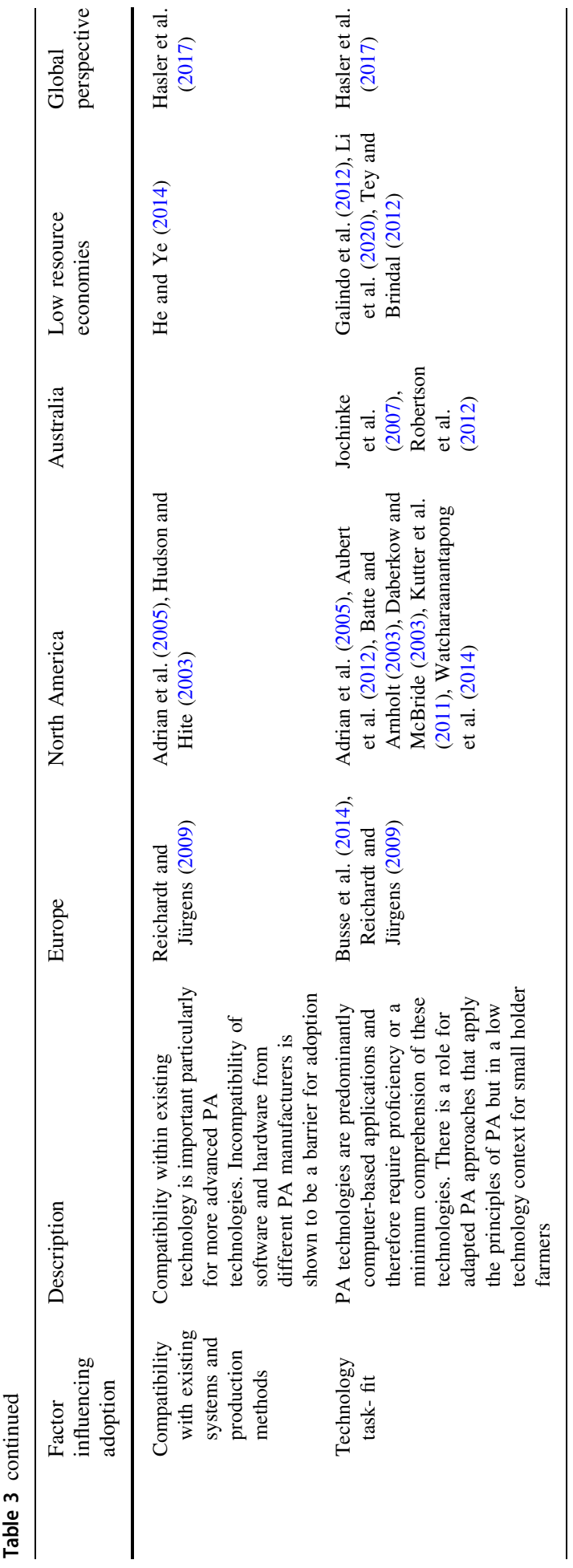




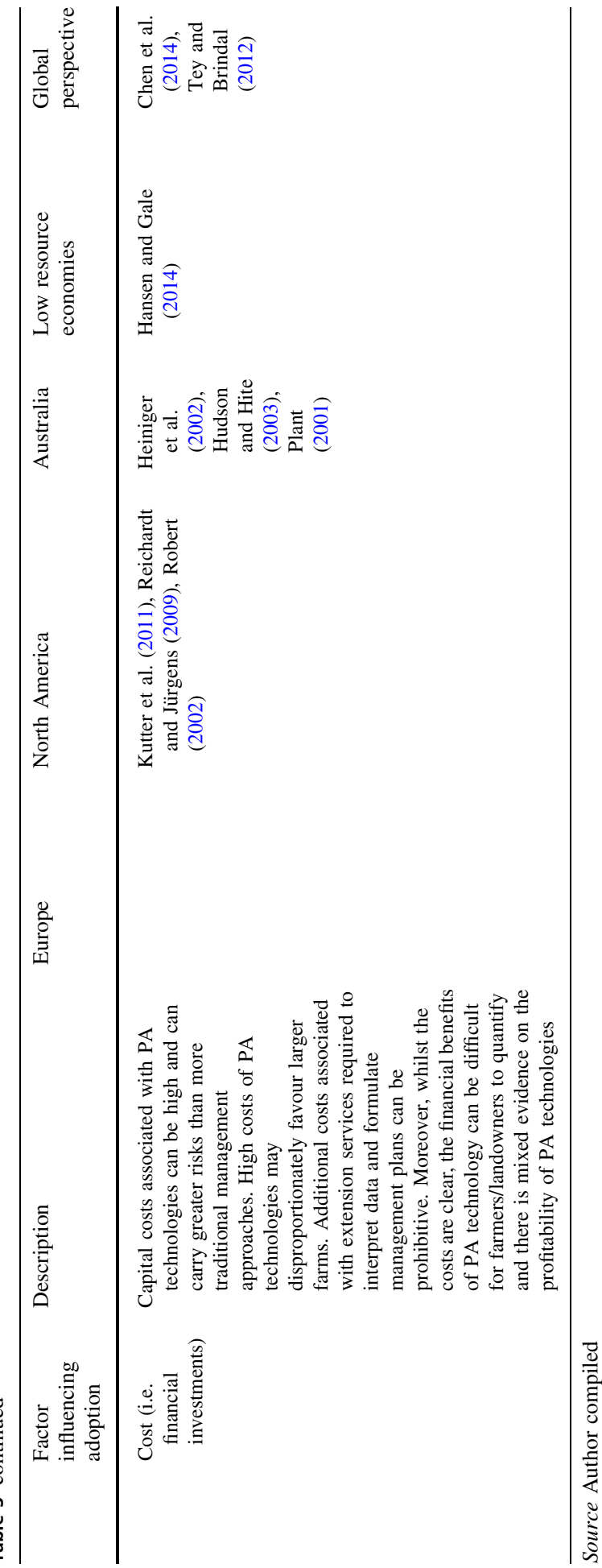




\section{Methodological approach}

\section{Research development}

Qualitative in-depth interviews were chosen for their ability to explore participant experiences. This method is suited to exploratory studies and the method is recognised to have cross cultural validity (see Kendall et al., 2017; Lofland \& Lofland, 1971). Whilst the approach does not allow for the generalisation of findings to wider populations, it does provide opportunity to deeply engage with potential end-users and unpick the factors that motivate, support, or inhibit adoption (Bryman, 2016). An initial discussion guide informed by the literature and theories of technology adoption was developed. The study protocol was also informed by exploratory qualitative research conducted by the lead authors with Chinese farmers and Chinese agricultural policy makers, with both used to develop an understanding of contextual issues for more detailed exploration (Kendall et al., 2017). Interviews were semi-structured and conducted in English and simultaneously translated into Mandarin or the local dialect. A semi-structured approach provided both focus on core topics and flexibility based on participant responses, and is particularly useful when multiple researchers are conducting interviews to ensure consistency (Bryman, 2016). Ethical approval for the project was granted by Newcastle University Ethics Committee (March 2018) and for the pilot (July 2016).

A discussion guide was piloted with ten Chinese farmers located in the Beijing region in November 2017 to check the accuracy, suitability of the question areas and comprehension of meaning and interview timing. The pilot revealed that participants found it particularly difficult to discuss in any detail commonly available PA technologies owing to their limited awareness and experience of them. Pilot interviews were dominated by discussion of demographics, farming practices and agronomic challenges. In order to ensure construct validity, these findings were used in conjunction with the study aims (Yin, 2014) to prepare a revised (final) discussion guide for data collection (April 2018). The discussion guide focused on several key concepts identified within the literature to potentially impact adoption of agricultural technologies including: the challenges faced by family farmers in China, their level of existing technology adoption, perceived level of technology adoption readiness and potential mechanisms to support PA technology adoption amongst family farmers. Contextual demographic farm information was collected by questionnaire prior to commencing the interview. The final discussion guide contained five broad question areas (Table 4).

Question probes were included to prompt further inquiry, and interviewers were encouraged to investigate interesting lines of enquiry verbally. Prompt cards were used as discussion aids, specifically in the "Technology adoption" and "Mechanisms to support uptake" sections of the discussion guides. The cards were particularly useful in helping to familiarise participants with a range of technologies from simple to more advanced PA technologies e.g., Remote sensing, GIS and VRT). All materials were translated from English to Mandarin and back translated. Each interview lasted approximately $1 \mathrm{~h}$. All interviews were recorded verbatim and were translated from Mandarin to English for analysis. 
Table 4 Discussion guide content; family farm managers

\begin{tabular}{|c|c|c|}
\hline Section & Section title & Questions (broad focus) \\
\hline 1 & $\begin{array}{l}\text { Your farm and agricultural policy in } \\
\text { China }\end{array}$ & $\begin{array}{l}\text { Changes to land and crops } \\
\text { Duration of time on land lease } \\
\text { Support or benefits received from cooperative }\end{array}$ \\
\hline 2 & Farming practices and challenges & $\begin{array}{l}\text { Changes (over the last } 10 \text { years) and challenges to } \\
\text { farming practice } \\
\text { Strategies to address challenges and additional needs }\end{array}$ \\
\hline 3 & Technology adoption & $\begin{array}{l}\text { Perceived technology readiness (Rogers, 1962) } \\
\text { Current level of technology adoption } \\
\text { Adoption motivation(s) } \\
\text { Benefits/risk factors preventing adoption } \\
\text { Required improvements to support adoption }\end{array}$ \\
\hline $4^{\mathrm{a}}$ & $\begin{array}{l}\text { Mechanisms to support technology } \\
\text { uptake }\end{array}$ & $\begin{array}{l}\text { Agricultural policies } \\
\text { Financial incentives } \\
\text { Agronomic services } \\
\text { Knowledge exchange } \\
\text { Agricultural extension } \\
\text { Others }\end{array}$ \\
\hline 5 & Summary/wind down & Opportunity to review and add to the discussion \\
\hline
\end{tabular}

${ }^{a}$ Additional section of questions added post pilot

\section{Recruitment and sample}

Data were collected in two primary locations, Hebei (Shijiazhuang) and Shandong (Zibo). These represented regions in the North China Plain predominated by family farms and were locations in which project partners had demonstration sites. Recruitment and translational support were also provided by project partners NERCITA. Purposeful sampling was adopted to identify "family farmers" that would be able to talk with experience in relation to the study aims (Palinkas et al., 2015). Selection criteria ensured that participants were, (1) part of the farming community in Hebei (Shijiazhuang) and Shandong (Zibo); (2) were the principle farmer of their land (i.e., farm manger); (3) had at least 1 year's farming experience within these locations, and; (4) their farm was classified as a 'family farm' (i.e., operating at a commercial scale but managed and primarily operated by a single family). Consistent with the exploratory nature of the study the final sample consisted of $n=27$ arable farmers across the two study locations. All participants were remunerated for their time and contribution to the research, this was in line with local practice. Consistent with methodological recommendations interviews were conducted until data saturation was reached (Bryman, 2016).

\section{Data analysis}

Field notes were taken by the lead researchers (HK, BC) during and after the interviews were conducted. These included thoughts on the interview content and reflections on the interview and the research process itself. Thematic data analysis was supported by qualitative analysis software Nvivo (2016), and followed a three-stage process. First, interview transcripts were open-coded (Glaser \& Strauss, 1971) and an initial coding framework was developed by the lead author (HK). Second, the coding framework was refined. Three 
members of the research team (HK, BC and SJ) independently coded a selection of the transcripts and compared codes against the framework. This inter-coder reliability process followed three iterations until there was agreement that the categories within the framework reflected the data. The third stage of analysis involved three members of the research team coding the full data set into the coding framework (HK, BC and SJ). Overarching themes emerging from the data were discussed and finalised.

\section{Results}

\section{Overview}

Twenty-seven interviews were conducted from 12th to 19th April 2018 ( $\mathrm{n}=16$ farmers with one of these also acting as research hub manager/farmer in Zibo, Shandong Province; $\mathrm{n}=11$ farm managers in Shijiazhuang, Hebei Province) (Table 5). The sample comprised of 18 males and 9 female participants (age range from 41 to 67 years). Participants had a median of 30 years farming experience (range between 3 and 50). The median farm size was $200 \mathrm{mu}$ (approx. 13 hectares: range between 10 and $1400 \mathrm{mu}$ ). One farmer (participant 10) had moved to the Shandong region to establish an ecological farming business, although this was not typical of the sample. The remainder farmed responsibility land alongside land that had been transferred from other farmers. For most farmers, increases in farm size through land transfer had occurred within the last decade. Two farmers specialised in horticulture in greenhouses in addition to arable farming. Farmers planted staple crops, predominantly wheat and maize with small proportion also planting soybean, a lower yielding but higher market value crop. A small number of farmers had diversified into the production of fruits and vegetables for which higher market values could be obtained.

\section{Emergent themes}

Five central themes emerged from the data "socio-political landscape", "farming culture", "agricultural challenges", "adoption intentions (barriers/facilitators)" and "practical support mechanisms" (Fig. 1). These themes were representative of a mix of internal, external and technological factors that were all likely to influence the level and rate of adoption of PA technologies amongst family farmers. The findings are discussed under these theme headings and linkages between the respective themes explored supported by illustrative quotes from participants which have been adjusted, to correct English whilst maintaining meaning.

\section{Socio-political landscape}

Societal and political influences were shown to shape Chinese agriculture and influence awareness and adoption of PA technologies amongst participants. Despite policy directives aimed at modernising the nations approach to agricultural production, including those aimed at increasing production efficiencies and reducing the environmental impacts of production, limited consideration was given to the wider environmental impacts of agricultural production by participants with limited reflection given to the personal responsibilities of farmers to reduce the environmental impact of farming. Farmers were production orientated, welcoming opportunities to increase farm scale and intensify production to 


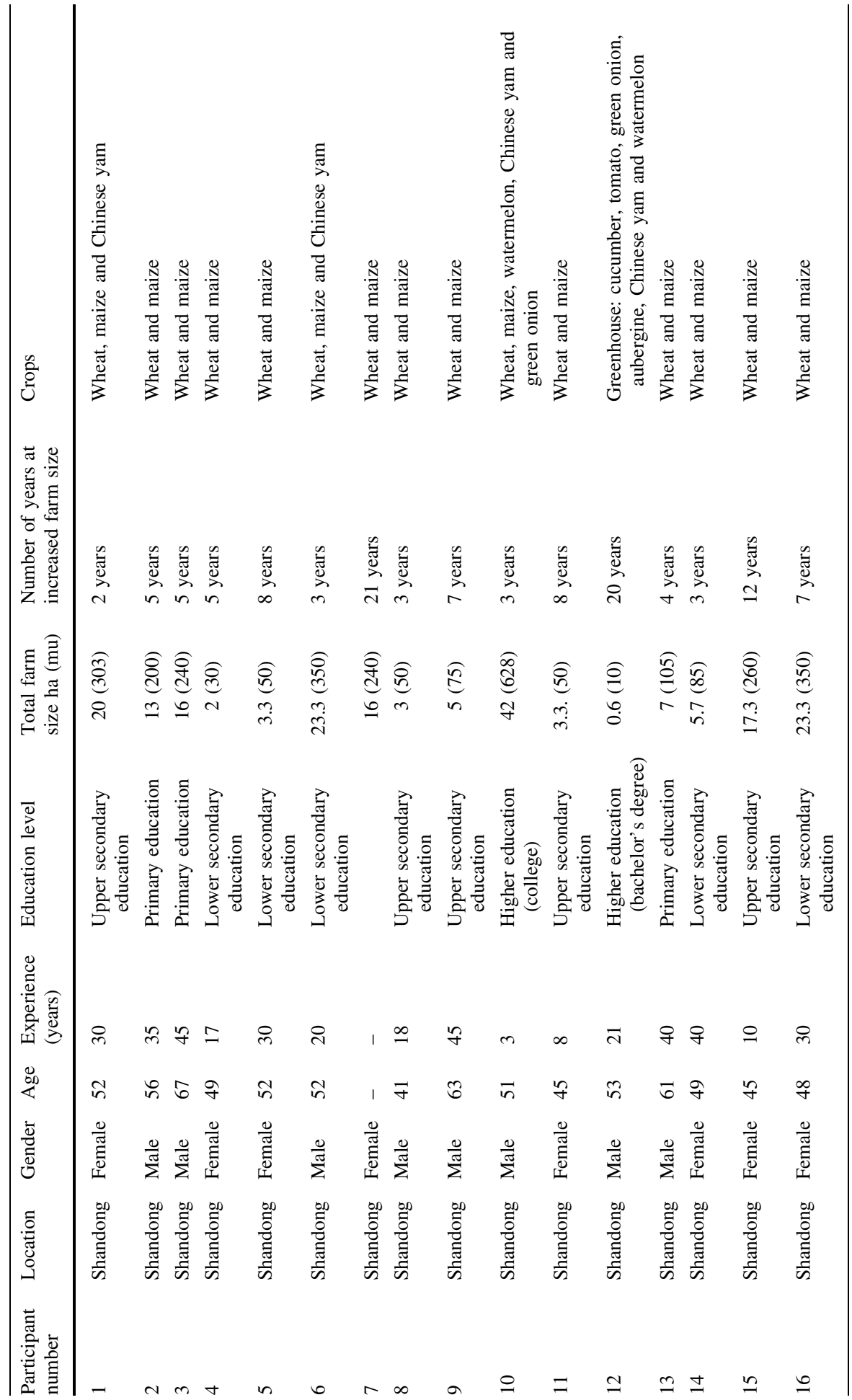




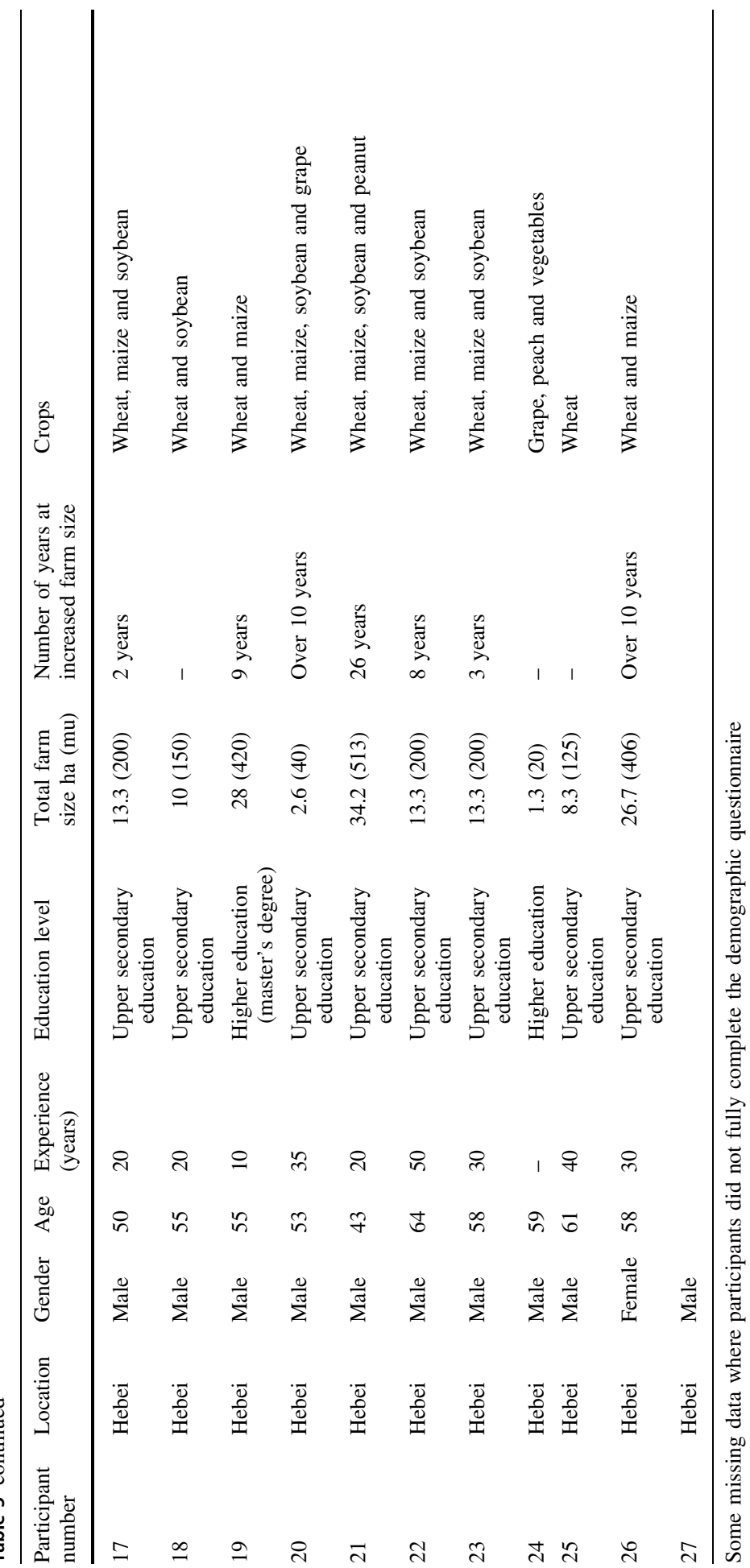




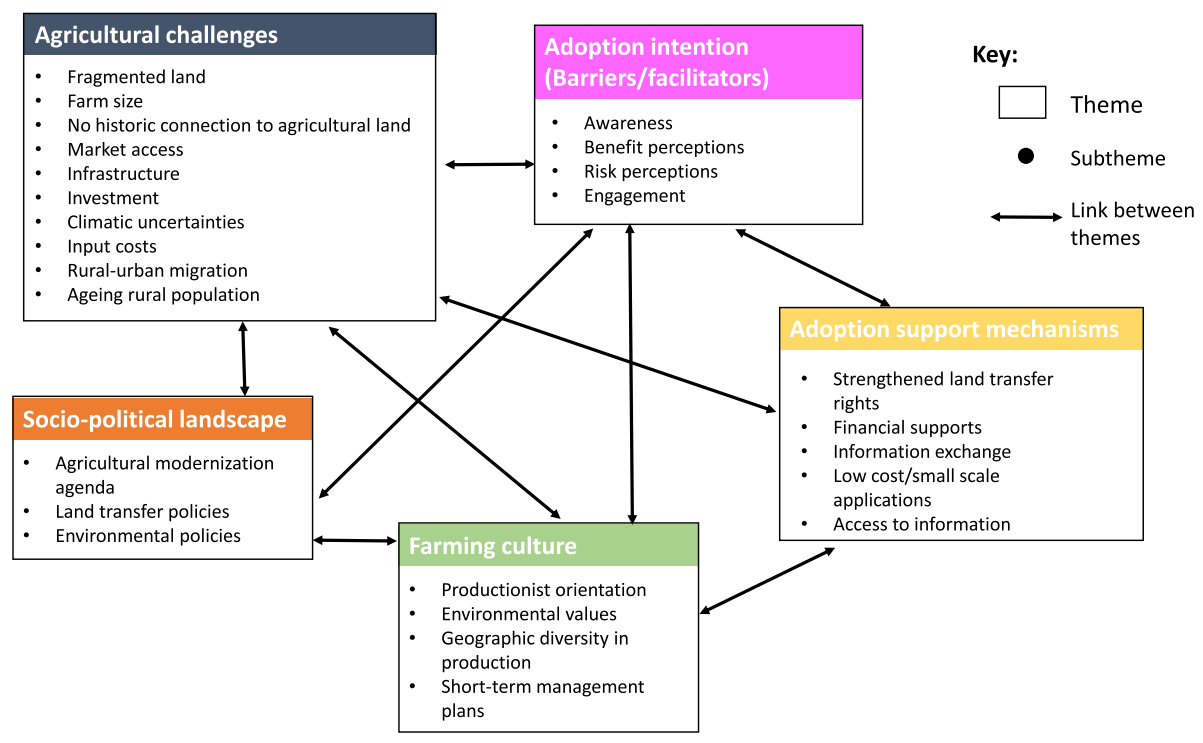

Fig. 1 Themes and subthemes from the interview data

counter low market values for yields. All participants had benefitted from the opportunity to transfer land, noting this to have increased the scale of their production significantly over the last decade.

Participants recognised that 'in practical terms it [acquiring land through transfer] is not that easy' (participant 19). Competing Chinese government policy agendas were identified to affect farming communities with implications recognised for the rate of land transfer, farm size growth and impact upon prosperity that could be derived from agricultural production. In parallel with the need to increase agricultural productivity and sustainability, the Chinese government is committed to reducing the environmental impacts of agricultural production by significantly reducing the countries usage of agri-chemicals alongside mitigating the degradation of the nation's forests (a consequence of a result of rapid population growth). Many respondents noted government policies aimed at forest conservation and restoration of forest ecosystems that have been initiated (e.g., Sloping Land Conversion Program (SLCP) and the National Forest Protection Program (NFPP)) (Bennett, 2008; Rodríguez et al., 2016; Wenhua, 2004). Through the SLCP scheme public payments are available to rural households to convert agricultural land to 'ecological forests' (for timber production), 'economic forests' (orchards or forests with medicinal value) or to grassland:

Our country wants farmers to cultivate forests, so they don't have very much field to cultivate [crops] (participant 22)

You are not able to expand it [farm land]. You know... look at my geographic location, now it is all covered with trees, [I] cannot transfer anymore [land]. (participant 25)

Participants located in Shijiazhuang noted the impact of these schemes on their ability to increase farm size, with many farmers choosing to convert land to forest conservation, as the subsidies received were greater than profits that could be made from agriculture. This 
reduced land availability increased the costs of land available for transfer and, was noted to contribute to the fragmentation of farm plots. This policy initiative was identified to be a primary factor preventing farmers from increasing farm size and the scale of production. Farm scale was noted to be a significant barrier to the suitability, applicability and likely adoption of PA technology on farm.

You can earn more than 1000 yuan for planting trees on $1 \mathrm{mu}$ [of land] but only hundreds for crops. (participant 26)

\section{Farming culture}

Despite increased farm size, farmers maintained traditional low-level mechanisation farming methods and operated short-term management plans for their farms with none exceeding 5 years. This was possibly attributable to the short length and informality of land transfer contracts. Most farmers demonstrated productionist orientations and were driven primarily by the need to increase the profitability of their farms, in direct response to market challenges. Economic drivers and incentives to increase farming profits were important motivators behind decisions made on farm, including decisions regarding the adoption of PA technologies. Decisions to increase land ownership and the scale of farm operations via land transfer were driven by the need to increase profitability given the broad recognition that you "you earn very little in agriculture" (participant 23). A small proportion of farmers had diversified production, producing speciality produce that commanded higher market values. The diversity of crops grown across a region was identified to present challenges to technology design and logistical challenges in relation to delivering agri-extension support services.

Farmers just grow crops that have a higher market value. So this may, bring a big challenge to agricultural extension services. Because the crops planted in this region might vary...so for agricultural extension and service providers, it means that there isn't a uniform technology that can be provided. It's quite fragmented (participant 27)

Farmers only made links to the production efficiencies and economic benefits of PA technologies with limited consideration of the potential environmental co-benefits. There was limited evidence of active environmentally regenerative farm and land management practices and equally limited recognition of the potential role that PA could play helping farmers to improve the environmental impact of agricultural production and meet incoming national legislation and agri-chemical usage targets. Participants showed limited awareness of future policy initiatives and legislation, including the cap on agrichemical use and conversely reported significant increases in their usage, necessitated by the need to guarantee yields to improve economic prosperity from farming.

\section{Agricultural challenges}

Various interlinked challenges acted as barriers to PA adoption but also represented opportunities for the development of PA applications to address farmer needs. Challenges were linked to economic, socio-demographic, political, landscape-related, infrastructural and environmental factors. Low economic returns combined with steadily increasing input and labour costs were further confounded by difficulties in accessing markets. The sociodemographic composition of rural communities had changed in recent decades, as a direct 
consequence of significant economic growth in urban conurbations, which had resulted in considerable rural-urban migration of younger members of the community for educational and employment opportunities. Others had used land transfer legislation as an opportunity to rent out their responsibility land and had sought higher paid employment in cities.

it's not worth it to farm just 1 or $2 \mathrm{mu}$ of land. The younger generation would just leave the village and find jobs outside, especially the men...So, of course young people don't want to farm... Farming is hard and you can't make much money out of it (participant 23).

It takes time and investment to achieve high levels of mechanization. Now we face many challenges in terms of land transfer...Given another 10 to 15 years, it would be easier to gather farmland because few people of the next generation will engage in farming. (participant 19)

The average age of farmers, as well as the scarcity of agricultural workers, increased the cost of labour, particularly at peak periods of the agricultural calendar (i.e. harvest).

The changes have been huge. I have engaged in agriculture for over 30 years. A prominent change in the past ten years has been the increase in labour costs. Seeds as well (participant 19)

Environmental challenges were primarily associated with climatic uncertainties. Many reported droughts impact due to limited underground water supplies, inadequate well facilities and the reliance on inefficient and outdated irrigation methods, exaggerated by inefficient irrigation solutions. Lodging in conditions of rain, hail and wind was also reported resulting in significant crop loss, exacerbated by a lack of space for, and the cost of, storing crops.

"One of the biggest problems is irrigation. Suppose there was a heavy rain in the fields, I don't need to irrigate for a period of time. But when you discover it needs irrigating, the crops are already in drought.' (participant 19)

One of worst natural disasters here is of course the wind, and also the hail, hailstones...usually the wheat, wheat suffers the most from hail. (participant 24)

The biggest problem is not having space for crop storage. When the weather is bad, the crops get wet and turn bad. It's rather problematic. (participant 21)

Land reforms resulted in many farming larger farms including land which they had no historic connection, often a collection of variable small holder plots fragmented across villages. This reduced the suitability of many precision farming technologies (typically designed for larger continuous areas):

"On my farm, I have 50-mu chunks or 40-mu chunks. But for theirs [other farmers], many fields are fragmented, $1 \mathrm{mu}$ over here and $1 \mathrm{mu}$ over there. That's impossible to work on.' (participant 23).

Land fragmentation occurred because of responsibility land farmers being unwilling to rent their land to others (commonly referred to as 'nail houses') or farmers adhering to policy pressures and cultivating their land for alternative purposes e.g. converted to forestry or grassland. Rapid farmland expansion created additional problems linked to the ability to invest in adequate infrastructure, such as storage for harvested crops, and more efficient methods of irrigation as noted. There was an underlying perception that investments made on farm were not recouped in profits and short-term tenancies resulted in a reluctance to invest in farm infrastructure, and supported a culture of intensification. Further challenges, 
such as the placement of transport infrastructure, were beyond farmers control and impacted their ability to increase farm size and the potential suitability of PA technologies were reported.

We are confined by the landscape. $600 \mathrm{mu}$ is upper bound. We have high speed roads running along the south and the north border of the farm. There is not much space to expand. (participant 19)

\section{Adoption intention (barriers/facilitators)}

Farmers showed a willingness to consider technological solutions to the agricultural challenges faced. Intention to trial and subsequently adopt PA technologies was shaped by five factors (sub-themes) discussed below.

\section{Awareness}

Awareness and adoption of PA technology varied according to individual farmer attributes and PA applications. Farmers with formal agricultural education showed greater awareness and engagement with PA technologies and were incentivised to keep up to date in technology developments. Formally educated farmers had a broader knowledge of PA applications and understanding of the suite of PA technologies available. Interestingly some farmers perceived themselves to be more innovative than their behaviours revealed.

One farmer reported that proximity to a demonstration farm had given them first-hand experience of PA applications. However, adoption of PA was not sustained beyond the duration of the demonstration project. The majority of farmers in the sample were aware of Global Navigation Satellite Systems (GNSS) (i.e., GPS) although none owned machinery on which this was enabled. Regional promotion had resulted in the widespread awareness and adoption of some PA applications, for example. UAV's were used for spot spraying of pesticides, with awareness generated through regional promotion initiatives as a resource efficient means of agri-chemical application. Participants considered this technology to be an inexpensive and financially accessible for most small-scale farmers. Awareness of more advanced PA technologies, i.e., VRT such as remote sensing and hyperspectral imaging, was extremely limited amongst participants. Where farmers demonstrated an awareness of these technologies information was gained through informal peer-based networks, facilitated by widespread adoption of smart phones (e.g. farmers' group chat via cooperative membership, peer networks and WeChat, a Chinese messaging, social media and payment app) and television, rather than through more formal mechanisms such as research institutes, companies or agronomy services providers.

I have seen drones [UAV's] used for pesticide applications but I haven't used them in my field... [I use] tractor... for ploughing and planting seeds (participant 22) Actually, I knew of it [UAV's] a long time ago.

(Interviewer: where do you get the information? what format was this information in?)

Some information was via my smartphone, sometimes this was posted by my friends' in their moments on WeChat, and I also watch television programmes that have provided me with information ${ }^{7}$ (participant 10). 


\section{Engagement}

Awareness had not translated into engagement via trial or adoption for most PA technologies. Farmers relied predominantly on traditional farming machinery, i.e., tractors, and seeding machines, that were rented through machine cooperatives. The cost of technology and low profitability of farming were the primary reported barriers to trial and adoption. Farmers were unsure about where to access technologies and formal information provision mechanisms (i.e., agronomists) beyond the information and technologies that were promoted by government sponsored annual training programmes and demonstration projects, and perceived there to be an absence of local agricultural extension agents.

The use of UAV's for agrochemical applications was an exception with adoption common, particularly amongst farmers in Hebei, which had been a government sponsored demonstration area where UAV's had been promoted for time and labour efficiencies. Promotion had been effective in initiating farmer engagement. Participants considered UAVs to be affordable (comparable to other technologies) and easy to implement requiring limited operator skills or training. For other technologies, uptake had not extended beyond trial within demonstration projects, with cost cited as the primary barrier to long-term adoption alongside the lack of commercial service providers.

Drone spraying here is used when the crops sprout. It's used in winter, autumn and in spring. Maize as well, it's sprayed after sprouting. (participant 23)

That drone, I have two.

(Interviewer: Do you provide drones to other farmers?)

Yes. (participant 25)

In the absence of commercial service providers, there was evidence of collaboration and informal rental markets emerging via peers for those that could not afford to invest directly in technologies. For example, one farmer (participant 19) had adopted laser land levelling technology on his own farm and, in the absence of a company/agronomy service provider, had established a company providing this service to farmers in his region. However, this level of innovation was not typical:

I have been doing laser levelling for four years, I am the first in Hebei... When I went to the United States for an agricultural inspection in 1992, I had the impression that on the irrigated land there, the water flowed neatly. When I encountered this problem, I spoke to someone and later found out about laser levelling. Then I searched it online and found that there was a company named Tianbao selling laser levellers in China at that time. [....] The company is in Beijing. I bought two levellers from this company and have used them in my experimental field. (participant 19)

\section{Perceived benefits}

The perceived benefits centred around PA's potential for economic advantages through the reduction of inputs (e.g., time, labour and seeds and agrochemicals) whilst simultaneously increasing yield. Improvements to crop quality were considered to increase profits via the market appeal and value of products. PA technologies were recognised as time saving, reducing labour expenditure and allowing farmers to engage in alternative farm management activities at appropriate times. For example, drip irrigation was recognised to improve efficiency, allowing farmers to quickly respond to variations in weather and soil 
moisture. Broader factors that might influence adoption were mentioned, although economic benefits predominated discussions.

We can see the advantages of the machines...I want all machine operations including seeding, pesticide spraying and harvesting in line with the field size. They can improve farming efficiency. I've been looking for GPS so that I can make the field banks straight. (participant 20)

Wider land management and environmental benefits of PA were not considered, including the potential of PA to reduce pesticide, fertiliser and herbicide application. The primary focus on farm profitability, and the lack of consideration of the wider environmental and land management benefits, aligns with the issues explored within the theme 'farming culture', particularly the productivity focused identities and the short-term orientation of family farmers in China.

\section{Perceived risks}

The perceived risks associated with the adoption of PA technologies represented a barrier to adoption. Although there was some appreciation of the potential benefits that PA could deliver, the capital investment that such technologies require, and the perceived lack of cost/benefit information to support decision-making of adoption, represented important risks.

Just the investment is big... Too much investment. (participant 6)

Nothing could be done without money...I couldn't use the new technology if I don't get loans. (participant 22)

I want [to adopt]. But I have no money. We don't have things like this here. Drones

[UAV's] are quite advanced here. (participant 26)

Participants were aware of government subsidies to support adoption. However, access was limited by: farm size; whether subsidies covered the full cost of adoption; the prescribed nature of subsidies issued to landowners and not managers (i.e., to the owners of responsibility land and not for land rented), and; only permitted farmers to purchase technologies that were approved by the government.

Concerns were raised about the performance and reliability of technology and whether it could deliver the claims made. For example, many farmers with UAV's highlighted issues with battery life and size, chemical holding capacity and concerns around chemical evaporation.

So the bottleneck now is, for drones [UAV's], we need a breakthrough regarding the battery issues...The battery life sucks; so far the bottleneck hasn't been resolved. Apart from that...the battery takes up the space, right...adds to the weight, so the loading capacity suffers (participant 10).

Farmers had limited awareness about the sourcing and appropriateness of more advanced PA technologies. Many had not observed or trialled these technologies so benefits were difficult to quantify. Farmers were concerned about their ability to learn new systems, operate machinery and interpret data, and did not consider there to be adequate practical support available to aid the integration of technologies into existing practice. Farmers questioned their ability to financially benefit from technology adoption, based on demographic factors including age and the reduced likelihood of intergenerational succession as a consequence of migration trends. 
"It [UAV's] is surely is great if I knew how to use it.' (participant 21)

(Interviewer: Have you ever thought of buying one yourself?)

Maybe. But it's not suitable. I'm old' (participant 26)

Concerns were also expressed about the potential for mechanical failure, lacking the knowledge and skills to fix machinery or having this available locally, and the unforeseen costs that this might incur.

of course, there are risks...for example, like mechanical malfunction... things like that. (participant 10)

Openness towards technology and level of adoption readiness varied. Some farmers demonstrated characteristics from which they could be considered 'innovators' (Rogers, 1962), specialising in production methods including ecological farming and greenhouse horticulture (in addition to arable faming) (participants 10 and participant 12) and developing close relationships with those developing technologies (laser land levelling) to address farming problems (Participant 19). Others perceived readiness to adopt did not align with their actual level of engagement with technology. Many perceived themselves to be 'innovators' characterised by taking an active role in understanding new technologies and willing to try innovations despite unproven benefits and with some risk that adoption might be unprofitable (Clark et al., 2018; Rogers, 1962). However, this was contradicted by their (low) level of engagement with technology and limited awareness and knowledge of both established and emerging PA technologies. Farmers did not want to be early adopters yet were aware of the risks of being left behind and were persuaded to adopt technologies after the benefits of technologies have been proven (Rogers, 1962). These farmers were less likely to adopt technologies that required significant change to their existing practice and were more likely to consider adopting technologies that could be incorporated easily into their existing farm management practices.

'would use the new technology when I see others use it [first]. If you wait to see the benefits, everybody would like to use it for sure. I am willing to try new technologies. (participant 21)

The one I bought [UAV] was a decision made from seeing others use it; that's why I bought one for myself as well (participant 1)

\section{Adoption mechanisms}

Farmers were enthusiastic about being involved in the research and development of technologies. Whilst "co-production" has been advocated in scientific communities (Clark et al., 2018; Cui et al., 2014), farmers expressed difficulties engaging with researchers beyond expected attendance at annual government training initiatives and supported visits to demonstration farms. Despite willingness to engage, farmers had limited knowledge of how best to engage and consequently reported waiting for information and technologies to reach them. Information was shared informally, via peer-based networks including hearing and seeing neighbours adopting new approaches. Participants recognised the need for more professional and effective platforms for information exchange; including a role for local extension agents, to provide more comprehensive and targeted information and build trust.

Policy support. The government has invested a lot of money to build high-quality farmland, and I think there should be policy in place to guide the process. I think it 
would be great if the policy can promote the use of land levelling and soil quality improvement in this region. (participant 19)

Participants expressed a need for policy to address the economic barriers which prohibit on-farm investment. Flexibility of government subsidies to include a wider range of technologies, reducing the limitations on farm size, as well as private low interest borrowing options to support investment in technologies were commonly cited.

We have subsidies for growing quality seeds and the crops-farming. But the subsidies only go to owners of the land, not people who actually farm the land. (participant 21)

From a policy perspective, farmers appreciated the fundamental role played by land reforms although suggested improvements to accelerate this, including: more formalised mechanisms for recording land transfer; improvements to contractual arrangements to increase farmer tenancy stability, and; facilitating long-term farm management planning and policy interventions to reduce land fragmentation.

\section{Discussion and policy implications}

This study found Chinese family farmers to be open to the potential of PA technologies, although heterogeneity in farmer perceptions of PA technology, willingness, and readiness to adopt were apparent. Awareness and use of the PA technologies was shown to be influenced by a combination of internal (i.e., farm and farmer characteristics) and external characteristics (i.e., observability, trialability and support), as well as those of the technologies themselves. Many of the internal and external factors, consistently shown within the literature (summarised in Table 3) to influence PA adoption globally, influenced adoption in this context. Although, several dimensions of these factors were specific to the Chinese agricultural context (see also Clark et al., 2018).

Farm size, land fragmentation and farming discontinuous plots was considered a fundamental obstruction to the modernisation of farming practice, including adoption of PA technologies. The socio-political landscape specifically, the land reforms in China, as well as policy tensions surrounding land use (i.e., conflicts between environmental, food management policies and agricultural modernisation) had impacted farmer's ability to increase farm size. The Chinese government may need to consider the trade-offs made by farmers because of policies in different domains (i.e., agricultural and environmental). Coherence across policies and improvements to the land transfer market to reduce fragmentation and uncertainties associated with tenancies, would allow for more long-term farm management planning and reduce the risks associated with making financial investment on farm. This would have multiple benefits, broadly helping to achieve agricultural modernisation goals, improve the suitability of existing PA technologies to small-scale farming as well as obtaining environmental co-benefits (Qian et al., 2016).

The suitability of technology for small scale farming is a fundamental barrier to adoption identified in other developing agricultural economies, e.g., India (Mondal \& Basu, 2009), and indicates the need for low-cost PA technologies better suited to smallscale farms that will benefit both farmers and the environment (Cheema \& Khan, 2019). Galindo et al. (2012) argue that site-specific agriculture is usually associated with high levels of technology, although demonstrate that providing approaches following the "observe-interpret- evaluate-implement" principles enables more low-tech approaches that are suitable and beneficial to smallholder farmers, supporting the arguments for improved 
understanding of the challenges faced by family farmers to support the design of and increase the relevance of PA applications, Future research should look to: (1) create technologies suited to small-scale, fragmented farmland; (2) look to adapt the provision of existing technologies to suit the identified challenges, and (3) have greater involvement from end-users alongside experts throughout the development process (Galindo et al., 2012).

Despite recognised and proven potential, and notable attempts made by the Chinese government over the last two decades to promote PA technology (e.g., via the establishment of demonstration centres), awareness, engagement, trial and adoption opportunities to engage with research and demonstration activities were perceived to be limited. The exception to this was the use of UAV for spot agri-chemical application. Here the economic benefits were quantifiable, and awareness and adoption had been facilitated through peer observation and more informal knowledge networks. Drones have more typically been utilised for data (image) gathering exercised in more developed agricultural economies. This difference is also more widely facilitated through the regulatory environment which allows for the use of UAV's for agrichemical application in China. Widespread adoption here reiterates the importance of information, observation and trial and knowledge exchange opportunities for increasing awareness and facilitating adoption (external factors). Research findings suggest that farmers who engage with and adopt PA technologies are more likely to consider adopting additional technologies (Winstead et al., 2010), there is a need therefore, for more targeted informational and educational opportunities alongside more frequent demonstration and field-days that specifically address the challenges faced by family farmers and stimulate initial trial (Heiniger et al., 2002). Future research should look to quantify the effect of different forms of knowledge provision and exchange on PA technology adoption, to identify those most suited to encouraging and importantly sustaining update, ensuring that heterogeneity in farm and farmer characteristics are acknowledged. The following paragraphs provide some suggestions for avenues to explore.

Findings identified two categories of farmers: (1) those who are pioneers and enthusiastically engage with and invest in PA technologies, although these were less typical of the sample, and; (2) those who were interested, although needed reassurances from observing others adopt, were not able to invest in technology directly, but were interested in service provision options. This suggests that market segmentation to differentiate adoption profiles would be useful to identify those most likely to lead adoption within communities and enable improved product positioning and targeting of local extension agents in disseminating information ( $\mathrm{Li}$ et al., 2020). Care needs to be taken to ensure a more objective measure of this, given that participants often reported higher levels of perceived technology readiness than their behaviours characterised.

In the absence of formal and regular educational opportunities, farmer awareness was typically gained via peer networks such as mobile phone platforms (WeChat), and observation of the benefits obtained by other farmers illustrated by the widespread adoption of UAV's as well as motivated by concerns about "being left behind". This highlights the importance of peer-to-peer support mechanisms and illustrates the value of supporting farmers to engage with these networks (Heiniger et al., 2002; Kernecker et al., 2020). Widespread adoption of mobile phone technology has been shown to reduce information asymmetry amongst farmers in developing agricultural economies (Aker, 2010; Ma et al., 2018). In the Chinese context, widespread adoption and reported reliance on internet and smartphone technology as a primary information sharing mechanism, has consequences for how technologies are disseminated though family farm communities. Providing there is the appropriate network coverage infrastructure in rural communities, smartphone and 
internet-based technology represents an opportunity to improve communication between researchers, agricultural policy makers, local extension agents and farmers (Aker, 2010; Ma et al., 2018). Although, differences in digital competencies amongst end-users must be recognised to avoid divisions within rural communities (Galindo et al., 2012).

Informal mechanisms for education and support should be coupled with more formal educational opportunities, with the level of engagement with PA also influenced by education level, with greater efforts to engage demonstrated by those with formal agricultural educations. Research indicates that encouraging skilled agricultural graduates back to rural communities can support the dissemination of PA technologies within rural communities. Therefore, there is an important role for relevant stakeholders is to acknowledge the value of both formal and informal education mechanisms to improve dialogue with end-users and in so doing improve current innovation trajectories (Clark et al., 2018; Heiniger et al., 2002; Qian et al., 2016).

Despite a low awareness and knowledge and PA technologies, farmers were principally motivated by the potential economic benefits that the adoption of PA technologies could bring, including improved profits and livelihoods from farming. This is unlike developed countries, such as the US, where evidence suggests farmers consider a broader range of benefits in addition to financial incentives, including, environmental benefits and increased convenience to the farmer when deciding to adopt (Thompson et al., 2019). However, whilst recognising the protential economic benefits farmers were inherently risk adverse and cautious about investing in technologies where the benefits were difficult to quantify, return on investment uncertain and adoption required end-users to make fundamental, and expensive changes to their farming practice (see also Hasler et al., 2017). This aversion to risk was compounded by the short-term approach to farm management planning by farmers, influenced by tenancy rather than land ownership, the informality of land contracts between and the low profitability of farming as well as demographic characteristics including age and succession status (Adesina \& Baidu-Forson, 1995). All of these have been shown to influence confidence and security in making on farm investment (Dean \& Damm-Luhr, 2010; Gao et al., 2017).

It is important to provide farmers with cost/benefit analysis data particularly in the decision-making stage to mitigate farmer concerns and reduce the perceived barriers related to economic risks. Future research is required to evidence the economic benefits PA adoption including economic studies that demonstrate that PA technologies can increase farm profitability (i.e., through resource efficacies) (Daberkow \& McBride, 2003; Schimmelpfennig \& Ebel, 2016). A further policy recommendation would be to consider reforms to the land transfer policies, providing market-based mechanisms for land purchase and ownership which is recognised to incentivise farmer investment in land improvements and technologies that may have multiple farm efficacies (Wainaina et al., 2016).

Finally, limited and poor access to information regarding financial support mechanisms such as subsidies and low interest credit further contributed to the perceived risk of adoption. Improved information and access across a spectrum of financial support mechanisms including credit, rental and affordable full-service provision and contractor options would reduce the economic barriers to adoption (Wossen et al., 2015). Agri-tech service providers have a vital role to play in reducing the influence of cost as a barrier to adoption by alleviating the need for long-term capital investments and the need for knowledge and skills acquisition by farmers by acting as professional consultants. In lieu of such services and as a means of improving farm profitability, farmers were shown to have established informal service provision networks. This finding illustrates the arguments presented 
regarding the importance of social capital as a determinant of technology adoption in low resource economies, and the importance of community networks to facilitate uptake in the absence of formal financial support and credit access. It also further demonstrates a demand and role for formal PA service provision, and raises concerns around the unregulated adoption of PA technologies, for example, the unregulated use of UAV's could carry risks to operators and bystanders. Farmers were open to, and recognised, a role for a topdown approach form the Chinese government to support adoption, with farmers acknowledging that for many, unless regulated, adoption of modern farm management mechanisms including precision technologies will be very slow to occur.

\section{Recommendation and limitations}

Research, policy and education supporting the adoption of PA technologies in developing agricultural economies should explicitly include farmers and end-users as key stakeholders in the process, from initial idea conception through the research and development process to product commercialisation as is advocated by institutions such as UK Research and Innovation the European Commission. This requires the role of farmers and end-users as the target market for PA technologies to be reframed and for them to be included as codevelopers of technology. This approach is consistent with the principles of 'Responsible Research and Innovation' (RRI) advocated by the European Commission and within the domain of PA (Clark et al., 2018).

Adoption success is influenced by a broad range of stakeholders in addition to farmers and end-users, including but not limited to, local policy makers, rural community members, agronomists and service providers. Future research should incorporate the views of these stakeholders in addition to farmers and end-users. The findings relate specifically to the experiences of family farmers in the North China plain, whilst our research highlights several themes likely to be similar across China, e.g., impact of agricultural policies, financial and information constraints, future research should consider the perspectives of farmers in other regions of China which may be exposed to different contextual factors.

Economic cost-benefit analysis and information regarding specific technologies is necessary to help mitigate the principle barrier to adoption (cost) including evidencing the long-term economic advantages to adoption, and improved translations and communication to support farmer decision making and improve uptake. Resources should be allocated for knowledge building, including demonstration, extension and information provision tailored to smallholder farmers, and is required to acknowledge the importance of utilising formal and informal educational channels, alongside technological development. Finally, differences in perceived readiness to adopt were identified, future research could quantitatively explore differences in farmer adoption characteristics to understand communication preferences and support more targeted communication with local farming communities.

\section{Conclusions}

Incentivising adoption to meet the 'ubiquitous' adoption ambitions of the Chinese government, requires consideration of the unique factors influencing adoption in the Chinese context. Whilst land reforms have provided the facilitating conditions for more widespread adoption, they have also created additional challenges (i.e., land fragmentation) that have acted as a barrier to uptake. Increasing rates of adoption requires clear understanding of 
these challenges and the unmet needs of farmers to reduce adoption barriers. A clear role for PA and untapped market opportunities for the researchers, developers and agronomic service providers of PA technologies in China was highlighted. Limited awareness of suitable and affordable technologies was identified as an important barrier to adoption, highlighting the need for small scale, low cost PA applications, improved information provision, finical support mechanisms including more accessible subsidies, and service provision, as well as, reliable implementation and aftercare support.

Acknowledgements This work was conducted as part of the PAFIC-Precision Agriculture for Familyfarms in China project, funded by the UK China Research and Innovation Partnership Fund (Newton Programme, STFC Ref.: ST/N006801/1; NSFC Ref.: 61661136003).

Funding This research was funded by the UK-China Research and Innovation Partnership Fund (Newton Programme: PAFIC-Precision Agriculture for Family-farms in China project, NSFC Ref.: 61661136003 \& STFC Ref.: ST/N006801/1).

Data availability All data is available from the corresponding author on request.

Code availability Not applicable.

\section{Declarations}

Conflict of interest The authors declare that they have no conflict of interest.

Ethical approval Ethical approval was obtained from Newcastle University (reference 4660/2018).

Consent to participate All participants provided informed consent to participate in the research.

Consent for publication All participants agreed to anonymous publication of research findings.

Open Access This article is licensed under a Creative Commons Attribution 4.0 International License, which permits use, sharing, adaptation, distribution and reproduction in any medium or format, as long as you give appropriate credit to the original author(s) and the source, provide a link to the Creative Commons licence, and indicate if changes were made. The images or other third party material in this article are included in the article's Creative Commons licence, unless indicated otherwise in a credit line to the material. If material is not included in the article's Creative Commons licence and your intended use is not permitted by statutory regulation or exceeds the permitted use, you will need to obtain permission directly from the copyright holder. To view a copy of this licence, visit http://creativecommons.org/licenses/by/4.0/.

\section{References}

Adesina, A. A., \& Baidu-Forson, J. (1995). Farmers' perceptions and adoption of new agricultural technology: Evidence from analysis in Burkina Faso and Guinea, West Africa. Agricultural Economics, 13(1), 1-9.

Adrian, A. M., Norwood, S. H., \& Mask, P. L. (2005). Producers' perceptions and attitudes toward precision agriculture technologies. Computers and Electronics in Agriculture, 48(3), 256-271.

Aker, J. C. (2010). Information from markets near and far: Mobile phones and agricultural markets in Niger. American Economic Journal: Applied Economics, 2(3), 46-59.

Aubert, B. A., Schroeder, A., \& Grimaudo, J. (2012). IT as enabler of sustainable farming: An empirical analysis of farmers' adoption decision of precision agriculture technology. Decision Support Systems, 54(1), 510-520.

Batte, M. T., \& Arnholt, M. W. (2003). Precision farming adoption and use in Ohio: Case studies of six leading-edge adopters. Computers and Electronics in Agriculture, 38(2), 125-139. 
Bennett, M. T. (2008). China's sloping land conversion program: Institutional innovation or business as usual? Ecological Economics, 65(4), 699-711.

Bryman, A. (2016). Social research methods (5th ed.). Oxford University Press.

Busse, M., Doernberg, A., Siebert, R., Kuntosch, A., Schwerdtner, W., König, B., \& Bokelmann, W. (2014). Innovation mechanisms in German precision farming. Precision Agriculture, 15(4), 403-426.

Chang, S. C., \& Tsai, C.-H. (2015). The adoption of new technology by the farmers in Taiwan. Applied Economics, 47(36), 3817-3824.

Cheema, M. J. M., \& Khan, M. A. (2019). Information technology for sustainable agriculture. In M. Farooq, \& M. Pisante (Eds.), Innovations in sustainable agriculture (pp. 585-597). Springer.

Chen, C., Pan, J., \& Lam, S. K. (2014). A review of precision fertilization research. Environmental Earth Sciences, 71(9), 4073-4080.

Clark, B., Jones, G., Kendall, H., Taylor, J., Cao, Y., Li, W., Zhao, C., Chen, J., Yang, G., \& Chen, L. (2018). A proposed framework for accelerating technology trajectories in agriculture: A case study in China. Frontiers of Agricultural Science and Engineering. https://doi.org/10.15302/J-FASE-2018244

Cui, Z., Dou, Z., Chen, X., Ju, X., \& Zhang, F. (2014). Managing agricultural nutrients for food security in China: Past, present, and future. Agronomy Journal, 106(1), 191-198.

Cui, Z., Zhang, H., Chen, X., Zhang, C., Ma, W., Huang, C., Zhang, W., Mi, G., Miao, Y., \& Li, X. (2018). Pursuing sustainable productivity with millions of smallholder farmers. Nature, 555(7696), 363-366.

Daberkow, S. G., \& McBride, W. D. (2003). Farm and operator characteristics affecting the awareness and adoption of precision agriculture technologies in the US. Precision Agriculture, 4(2), 163-177.

Dean, R., \& Damm-Luhr, T. (2010). A Current review of Chinese land-use law and policy: A breakthrough in rural reform. Pacific Rim Law \& Policy Journal, 19, 121.

Deichmann, U., Goyal, A., \& Mishra, D. (2016). Will digital technologies transform agriculture in developing countries? The World Bank.

Finger, R., Swinton, S. M., El Benni, N., \& Walter, A. (2019). Precision farming at the nexus of agricultural production and the environment. Annual Review of Resource Economics, 11, 313-335. https://doi.org/ 10.1146/annurev-resource-100518-093929

Galindo, P. A., Granell, C., Molin, P. G., \& Guijarro, J. H. (2012). Participative site-specific agriculture analysis for smallholders. Precision Agriculture, 13(5), 594-610.

Gao, L., Sun, D., \& Huang, J. (2017). Impact of land tenure policy on agricultural investments in China: Evidence from a panel data study. China Economic Review, 45, 244-252.

Gebbers, R., \& Adamchuk, V. I. (2010). Precision agriculture and food security. Science, 327(5967), 828-831.

Glaser, B. S., \& Strauss, A. (1971). The discovery of grounded theory: Strategies for qualitative research. Aldine Publishing Co.

Han, D., Liu, S., Du, Y., Xie, X., Fan, L., Lei, L., Li, Z., Yang, H., \& Yang, G. (2019). Crop water content of winter wheat revealed with Sentinel-1 and Sentinel-2 imagery. Sensors, 19(18), 4013.

Hansen, J., \& Gale, F. (2014). China in the next decade: Rising meat demand and growing imports of feed. Retrieved 13th April 2021 from https://www.ers.usda.gov/amber-waves/2014/april/china-in-the-nextdecade-rising-meat-demand-and-growing-imports-of-feed/

Hasler, K., Olfs, H.-W., Omta, O., \& Bröring, S. (2017). Drivers for the adoption of different eco-innovation types in the fertilizer sector: A review. Sustainability, 9(12), 2216.

Hauptman, H. (2018). Decade-Long Study Helps 21 Million Chinese Farmers Cut Fertilizer Use. Retrieved 2nd March 2020 from https://e360.yale.edu/digest/decade-long-study-helps-21-million-chinesefarmers-cut-fertilizer-use

Hayman, P., Crean, J., Mullen, J., \& Parton, K. (2007). How do probabilistic seasonal climate forecasts compare with other innovations that Australian farmers are encouraged to adopt? Australian Journal of Agricultural Research, 58(10), 975-984.

He, C., \& Ye, J. (2014). Lonely sunsets: Impacts of rural-urban migration on the left-behind elderly in rural China. Population, Space and Place, 20(4), 352-369.

Heiniger, R., Havlin, J., Crouse, D., Kvien, C., \& Knowles, T. (2002). Seeing is believing: The role of field days and tours in precision agriculture education. Precision Agriculture, 3(4), 309-318.

Huang, Y., Chen, Z.-x, Tao, Y., Huang, X.-z, \& Gu, X.-f. (2018). Agricultural remote sensing big data: Management and applications. Journal of Integrative Agriculture, 17(9), 1915-1931.

Hudson, D., \& Hite, D. (2003). Producer willingness to pay for precision application technology: Implications for government and the technology industry. Canadian Journal of Agricultural Economics/ Revue canadienne d'agroeconomie, 51(1), 39-53.

International Society of Precision Agriculture. (no date). Precision Ag Definition. Retrieved 12th April 2021 from https://www.ispag.org/about/definition 
Jawad, H. M., Nordin, R., Gharghan, S. K., Jawad, A. M., \& Ismail, M. (2017). Energy-efficient wireless sensor networks for precision agriculture: A review. Sensors, 17(8), 1781.

Jihua, M., Zhongyuan, L., Bingfang, W., \& Jin, X. (2014). Design, development and application of a satellite-based field monitoring system to support precision farming. 2014 The Third International Conference on Agro-Geoinformatics.

Jin, J., \& Jiang, C. (2002). Spatial variability of soil nutrients and site-specific nutrient management in the PR China. Computers and Electronics in Agriculture, 36(2-3), 165-172.

Jochinke, D. C., Noonon, B. J., Wachsmann, N. G., \& Norton, R. M. (2007). The adoption of precision agriculture in an Australian broadacre cropping system-Challenges and opportunities. Field Crops Research, 104(1-3), 68-76.

Ju, X., Gu, B., Wu, Y., \& Galloway, J. N. (2016). Reducing China's fertilizer use by increasing farm size. Global Environmental Change, 41, 26-32.

Kendall, H., Naughton, P., Clark, B., Taylor, J., Li, Z., Zhao, C., Yang, G., Chen, J., \& Frewer, L. J. (2017). Precision agriculture in China: Exploring awareness, understanding, attitudes and perceptions of agricultural experts and end-users in China. Advances in Animal Biosciences, 8(2), 703-707. https:// doi.org/10.1017/S2040470017001066

Kernecker, M., Knierim, A., Wurbs, A., Kraus, T., \& Borges, F. (2020). Experience versus expectation: Farmers' perceptions of smart farming technologies for cropping systems across Europe. Precision Agriculture, 21(1), 34-50.

Kuehne, G., Llewellyn, R., Pannell, D. J., Wilkinson, R., Dolling, P., Ouzman, J., \& Ewing, M. (2017). Predicting farmer uptake of new agricultural practices: A tool for research, extension and policy. Agricultural Systems, 156, 115-125.

Kutter, T., Tiemann, S., Siebert, R., \& Fountas, S. (2011). The role of communication and co-operation in the adoption of precision farming. Precision Agriculture, 12(1), 2-17.

Lamb, D. W., Frazier, P., \& Adams, P. (2008). Improving pathways to adoption: Putting the right P's in precision agriculture. Computers and Electronics in Agriculture, 61(1), 4-9. https://doi.org/10.1016/j. compag.2007.04.009

Lamba, P., Filson, G., \& Adekunle, B. (2009). Factors affecting the adoption of best management practices in southern Ontario. The Environmentalist, 29(1), 64-77.

Li, W., Clark, B., Taylor, J. A., Kendall, H., Jones, G., Li, Z., Jin, S., Zhao, C., Yang, G., \& Shuai, C. (2020). A hybrid modelling approach to understanding adoption of precision agriculture technologies in Chinese cropping systems. Computers and Electronics in Agriculture, 172, 105305.

Li, Z., Taylor, J., Frewer, L., Zhao, C., Yang, G., Liu, Z., Gaulton, R., Wicks, D., Mortimer, H., \& Cheng, X. (2019). A comparative review on the state and advancement of Site-Specific Crop Management in the UK and China. Frontiers of Agricultural Science and Engineering. https://doi.org/10.15302/J-FASE2018240

Liang, Y., \& Wu, W. (2014). Exploratory analysis of health-related quality of life among the empty-nest elderly in rural China: An empirical study in three economically developed cities in eastern China. Health and Quality of Life Outcomes, 12(1), 59.

Lin, F. (2020). Overview of China's New Pesticide Regulations. Retrieved 2nd March 2020 from https:// agrochemical.chemlinked.com/agropedia/overview-chinas-new-pesticide-regulations

Liu, J. (2014). Ageing, migration and familial support in rural China. Geoforum, 51, 305-312.

Liu, Y., Lu, S., \& Chen, Y. (2013). Spatio-temporal change of urban-rural equalized development patterns in China and its driving factors. Journal of Rural Studies, 32, 320-330. https://doi.org/10.1016/j. jrurstud.2013.08.004

Lofland, J., \& Lofland, L. H. (1971). Analyzing social settings: A guide to qualitative observation and analysis. Wadsworth Publishing Company.

Lowenberg-DeBoer, J., \& Erickson, B. (2019). Setting the record straight on precision agriculture adoption. Agronomy Journal, 111(4), 1552-1569.

Ma, L., Feng, S., Reidsma, P., Qu, F., \& Heerink, N. (2014). Identifying entry points to improve fertilizer use efficiency in Taihu Basin, China. Land Use Policy, 37, 52-59.

Ma, W., Grafton, R. Q., \& Renwick, A. (2018). Smartphone use and income growth in rural China: Empirical results and policy implications. Electronic Commerce Research, 20, 1-24.

Mikula, K., Izydorczyk, G., Skrzypczak, D., Mironiuk, M., Moustakas, K., Witek-Krowiak, A., \& Chojnacka, K. (2020). Controlled release micronutrient fertilizers for precision agriculture-A review. Science of the Total Environment, 712, 136365.

Mondal, P., \& Basu, M. (2009). Adoption of precision agriculture technologies in India and in some developing countries: Scope, present status and strategies. Progress in Natural Science, 19(6), 659-666.

NVivo. (2016). NVivo qualitative data analysis Software. QSR International Pty Ltd. 
Palinkas, L. A., Horwitz, S. M., Green, C. A., Wisdom, J. P., Duan, N., \& Hoagwood, K. (2015). Purposeful sampling for qualitative data collection and analysis in mixed method implementation research. Administration and Policy in Mental Health and Mental Health Services Research, 42(5), 533-544.

Pathak, H. S., Brown, P., \& Best, T. (2019). A systematic literature review of the factors affecting the precision agriculture adoption process. Precision Agriculture, 20(6), 1292-1316.

Paustian, M., \& Theuvsen, L. (2017). Adoption of precision agriculture technologies by German crop farmers. Precision Agriculture, 18(5), 701-716.

Peng, L., Chen, W., Li, M., Bai, Y., \& Pan, Y. (2014). GIS-based study of the spatial distribution suitability of livestock and poultry farming: The case of Putian, Fujian, China. Computers and Electronics in Agriculture, 108, 183-190.

Phillips, S. (2014). Precision agriculture: Supporting global food security. Science, 98, 4-6.

Plant, R. E. (2001). Site-specific management: The application of information technology to crop production. Computers and Electronics in Agriculture, 30(1-3), 9-29.

Qian, W., Wang, D., \& Zheng, L. (2016). The impact of migration on agricultural restructuring: Evidence from Jiangxi Province in China. Journal of Rural Studies, 47, 542-551.

Raley, M. E., Ragona, M., Sijtsema, S. J., Fischer, A. R., \& Frewer, L. J. (2016). Barriers to using consumer science information in food technology innovations: An exploratory study using Delphi methodology. International Journal of Food Studies, 5(1), 39-53.

Reichardt, M., \& Jürgens, C. (2009). Adoption and future perspective of precision farming in Germany: Results of several surveys among different agricultural target groups. Precision Agriculture, 10(1), 73-94.

Robert, P. C. (2002). Precision agriculture: A challenge for crop nutrition management. Progress in Plant Nutrition: Plenary Lectures of the XIV International Plant Nutrition Colloquium

Robertson, M., Llewellyn, R., Mandel, R., Lawes, R., Bramley, R., Swift, L., Metz, N., \& O'Callaghan, C. (2012). Adoption of variable rate fertiliser application in the Australian grains industry: Status, issues and prospects. Precision Agriculture, 13(2), 181-199.

Rodríguez, L. G., Hogarth, N. J., Zhou, W., Xie, C., Zhang, K., \& Putzel, L. (2016). China's conversion of cropland to forest program: A systematic review of the environmental and socioeconomic effects. Environmental Evidence, 5(1), 21.

Rogers, E. M. (1962). Diffusion of innovations. Simon and Schuster.

Sausmikat, N. (2015). Sustainable agriculture in China: Land policies, food and farming issues. https:// www.eu-china.net/uploads/tx_news/Sustainable_agriculture_in_China_web.pdf

Say, S. M., Keskin, M., Sehri, M., \& Sekerli, Y. E. (2018). Adoption of precision agriculture technologies in developed and developing countries. Online Journal of Science and Technology, 8, 7-15.

Schimmelpfennig, D. (2016). Farm profits and adoption of precision agriculture (No. 249773).

Schimmelpfennig, D., \& Ebel, R. (2016). Sequential adoption and cost savings from precision agriculture. Journal of Agricultural and Resource Economics, 41(1), 97-115.

Stombaugh, T. (2018). Satellite-based positioning systems for precision agriculture. In D. K. Shannon, D. E. Clay, \& N. R. Kitchen (Eds.), Precision agriculture basics (precisionagbasics) (pp. 25-36). American Society of Agronomy, Inc., Crop Science Society of America, Soil Science Society of America, ACSESS Publications.

Tey, Y. S., \& Brindal, M. (2012). Factors influencing the adoption of precision agricultural technologies: A review for policy implications. Precision Agriculture, 13(6), 713-730.

Tey, Y. S., Li, E., Bruwer, J., Abdullah, A. M., Brindal, M., Radam, A., Ismail, M. M., \& Darham, S. (2014). The relative importance of factors influencing the adoption of sustainable agricultural practices: A factor approach for Malaysian vegetable farmers. Sustainability Science, 9(1), 17-29.

Tey, Y. S., Li, E., Bruwer, J., Abdullah, A. M., Brindal, M., Radam, A., Ismail, M. M., \& Darham, S. (2017). Factors influencing the adoption of sustainable agricultural practices in developing countries: A review. Environmental Engineering \& Management Journal (EEMJ), 16(2), 337-349.

Thompson, N. M., Bir, C., Widmar, D. A., \& Mintert, J. R. (2019). Farmer perceptions of precision agriculture technology benefits. Journal of Agricultural and Applied Economics, 51(1), 142-163.

Wachowiak, M. P., Walters, D. F., Kovacs, J. M., Wachowiak-Smolíková, R., \& James, A. L. (2017). Visual analytics and remote sensing imagery to support community-based research for precision agriculture in emerging areas. Computers and Electronics in Agriculture, 143, 149-164.

Wainaina, P., Tongruksawattana, S., \& Qaim, M. (2016). Tradeoffs and complementarities in the adoption of improved seeds, fertilizer, and natural resource management technologies in Kenya. Agricultural Economics, 47(3), 351-362.

Wandkar, S. V., Bhatt, Y. C., Jain, H., Nalawade, S. M., \& Pawar, S. G. (2018). Real-time variable rate spraying in orchards and vineyards: A review. Journal of the Institution of Engineers (India): Series A, 99(2), 385-390. 
Watcharaanantapong, P., Roberts, R. K., Lambert, D. M., Larson, J. A., Velandia, M., English, B. C., Rejesus, R. M., \& Wang, C. (2014). Timing of precision agriculture technology adoption in US cotton production. Precision Agriculture, 15(4), 427-446.

Weber, C., \& McCann, L. (2015). Adoption of nitrogen-efficient technologies by US corn farmers. Journal of Environmental Quality, 44(2), 391-401.

Wenhua, L. (2004). Degradation and restoration of forest ecosystems in China. Forest Ecology and Management, 201(1), 33-41.

Winstead, A. T., Norwood, S. H., Griffin, T. W., Runge, M., Adrian, A. M., Fulton, J., \& Kelton, J. (2010). Adoption and use of precision agriculture technologies by practitioners. Proceedings of the 10th International Conference on Precision Agriculture.

Wossen, T., Berger, T., \& Di Falco, S. (2015). Social capital, risk preference and adoption of improved farm land management practices in Ethiopia. Agricultural Economics, 46(1), 81-97.

Xinhuanet. (2020). More than 98\% of the country's agricultural business entities are still small farmer. Retrieved 13th May 2018 from http://www.xinhuanet.com/politics/2019=03/01/c_1210071071.htm

Yin, R. K. (2014). Case study research and applications: Design and methods. SAGE Publications.

Zhang, W., Cao, G., Li, X., Zhang, H., Wang, C., Liu, Q., Chen, X., Cui, Z., Shen, J., \& Jiang, R. (2016). Closing yield gaps in China by empowering smallholder farmers. Nature, 537(7622), 671-674.

Zhao, W., Li, J., Yang, R., \& Li, Y. (2017). Yields and water-saving effects of crops as affected by variable rate irrigation management based on soil water spatial variation. Transactions of the Chinese Society of Agricultural Engineering, 33(2), 1-7.

Zhong, F., \& Zhu, J. (2017). Food security in China from a global perspective. Choices, 32(2), 1-5.

Publisher's Note Springer Nature remains neutral with regard to jurisdictional claims in published maps and institutional affiliations.

\section{Authors and Affiliations}

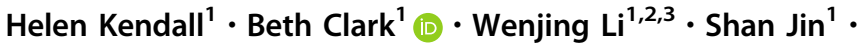

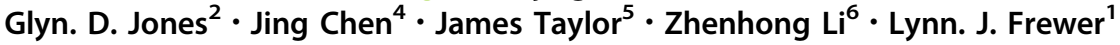

Beth Clark

beth.clark@newcastle.ac.uk

1 School of Natural and Environmental Science, Newcastle University, Newcastle upon-Tyne NE7 1RU, UK

2 FERA Sciences Ltd., National Agri-Food Innovation Campus, Sand Hutton, York YO41 1LZ, UK

3 College of Economics and Management, Huazhong Agricultural University, Wuhan, Hubei 430070, P.R. China

4 Institute of Agricultural Economics and Development, Chinese Academy of Agricultural Science, 12 Zhongguancun S St, Haidian District, Beijing, P.R. China

5 ITAP, Univ Montpellier, INRAE, Institut Agro, 34000 Montpellier, France

6 School of Civil Engineering and Geosciences, Newcastle University, Newcastle upon-Tyne NE7 1RU, UK 